\title{
A SIMULATION MODEL FOR DECISION SUPPORT IN BUSINESS CONTINUITY PLANNING
}

\author{
A Thesis \\ presented to \\ the Faculty of California Polytechnic State University, \\ San Luis Obispo
}

\author{
In Partial Fulfillment \\ of the Requirements for the Degree \\ Master of Science in Industrial Engineering
}

by

Marissa Mosunich

February 2016 
(C) 2016

Marissa Mosunich

ALL RIGHTS RESERVED 


\section{COMMITTEE MEMBERSHIP}

TITLE:

AUTHOR:

DATE SUBMITTED:

COMMITTEE CHAIR:

COMMITTEE MEMBER: Tali Freed, Ph.D.

Associate Professor of Industrial Engineering

COMMITTEE MEMBER: Xuan Wang, Ph.D.

Assistant Professor of Industrial Engineering
A Simulation Model for Decision Support in Business Continuity Planning

Marissa Mosunich

February 2016

Reza Pouraghabagher, Ph.D.

Professor of Industrial Engineering 


\begin{abstract}
A Simulation Model for Decision Support in Business Continuity Planning
\end{abstract}

Marissa Mosunich

Enterprises with a global supply network are at risk of lost revenue as a result of disruptive disasters at supplier locations. Various strategies exist for addressing this risk, and a variety of types of research has been done regarding the identification, assessment and response to the risk of disruption in a supply chain network.

This thesis establishes a decision model to support Business Continuity Planning at the first-tier supplier level. The decision model incorporates discrete-event simulation of supply chain networks (through Simio software), Monte Carlo simulation, and risk index optimization. After modeling disruption vulnerability in a supply chain network, costs of implementing all combinations of Business Continuity Plans are ranked and then tested in discrete-event simulation for further insight into inventory levels, unmet customer demand, production loss and related costs.

A case study demonstrates the implementation of the decision support process and tests a historical set of data from a large manufacturing company. Discrete-event simulation modeling of loss is confirmed to be accurate. The relevance of the model concept is upheld and recommendations for future work are made.

Keywords: Business Continuity Plan (BCP), discrete-event simulation, Monte Carlo simulation, risk index, risk management 


\section{ACKNOWLEDGMENTS}

I want to thank my family for their constant support, advisor Dr. Reza Pouraghabagher for

his "Sky's the limit" attitude, and Dr. Tali Freed who believed in my potential and encouraged me to explore uncharted waters. 


\section{TABLE OF CONTENTS}

LIST OF TABLES

Page

LIST OF FIGURES

viii

CHAPTER

1. INTRODUCTION

General Approach $\quad 2$

Issues and Assumptions $\quad 4$

2. LITERATURE REVIEW

Business Continuity Planning (General) 6

$\begin{array}{ll}\text { Risk-Oriented Decision Support } & 7\end{array}$

- Discrete-Event Simulation $\quad 8$

Risk Measurement $\quad 11$

Other Sources of Information $\quad 11$

3. SYSTEM DESIGN 13

Node Risk Profiles and Monte Carlo Simulation $\quad 15$

Discrete-Event Simulation: System Design 18

Part 2 Response Testing: BCP Choice Model- Combinatorial Risk Optimization 22

$\begin{array}{ll}\text { Response Testing in Simio } & 27\end{array}$

Part 2 Simulation Result Analysis $\quad 28$

4. SYSTEM IMPLEMENTATION 33

Supply Chain Disruption Risk Management Survey and Case 1 Input 33

Data Configuration 36

Risk Data Collection 36

Part 2 Implementation of Response Testing 39

Response Impact Configuration $\quad 40$

Simio Testing of Best Response Plans $\quad 42$

Cases 1A, 1B and 2 Implementation $\quad 44$ 
5. TESTING AND EVALUATION 46

Case 1 Testing 46

System Verification $\quad 49$

Part 2 Testing $\quad 50$

Cost-Benefit Ratio versus Net Savings

Case 1 Assessment in Simio $\quad 52$

Simulation Results and Cost Analysis $\quad 53$

$\begin{array}{ll}\text { Case 1B } & 57\end{array}$

Case 1B Results $\quad 58$

Comparison of BCP Choice Model Results and Simulation Results 64

6. CLOSING DISCUSSION 66

$\begin{array}{ll}\text { Findings } & 67\end{array}$

$\begin{array}{ll}\text { Research Limitations and Implications } & 68\end{array}$

$\begin{array}{ll}\text { Future Work } & 68\end{array}$

$\begin{array}{ll}\text { BIBLIOGRAPHY } & 70\end{array}$

APPENDICES

$\begin{array}{ll}\text { Appendix A } & 77\end{array}$ 


\section{LIST OF TABLES}

Table

3.1: Example Risk Profile with Monte Carlo Simulation

3.2: Example Monte Carlo Simulation Scenarios (3 of 1000) 17

3.3: Example server reliability logic settings, Simio Interface 19

3.4: Process settings, Simio Interface 22

3.5: Decision Matrix, BCP Choice Model 23

3.6: Example BCP Choice Model 25

3.7: BCP Response Impact, Example User Input 26

3.8: Response Cost Parameters, Example User Input 27

3.9: Example Top Choices, Sorted Decision List in BCP Choice Model 27

3.10: Example Response Scenarios, Simio Interface 28

3.11: Example Cost Analysis of Discrete-Event Simulation Results 30

3.12: Choice Model, Example Choice Cost vs. Benefit Comparison 31

4.1: Fukushima Risk Profile 37

4.2: Sendai Risk Profile $\quad 38$

4.3: Sendai 2 Risk Profile $\quad 39$

4.4: Case 1 Pre-Response Node Risk Parameters 39

4.5: Case 1, Response Choice Model, Sensitivity Input 41

4.6: Case 1, Response Choice Model Cost Input 42

4.7: Case 1 Post-BCP Risk Parameters 43

5.1: Case 1, Scenarios 1-4 Results, Simio Interface 47

5.2: Case 1, Scenario 6 Results, Simio Interface $\quad 47$

5.3: Case 1, Scenario 7 Results, Simio Interface 48

5.4: Case 1, Scenario 9 Results, Simio Interface 48

5.5: Case 1, Scenario 10 Results, Simio Interface 48

5.6: Case 1 Choice Model Results 51

5.7: Case 1 Choice Model Results 52

5.8: Case 1 Post-BCP Risk Parameters 53

5.9: Case 1 Optimal BCP Choices, According to Discrete-Event Simulation Results 54 
5.11: Case 1 Choice Model Results 57

5.12: Case 1B Choice Model Results 58

5.13: Case 1B Simulation Results, Simio $\quad 59$

5.14: Case 1B Simulation Results Cost Analysis $\quad 60$

5.15: Case 2, OEM Inventory Policy Scenario Results, Simio 62

5.16: Comparison of Net Savings Under Various Inventory Policies 63

5.17: Comparison of Risk Assessment and Simulation Results, Case 1B 64 


\section{LIST OF FIGURES}

Figure

Page

2.1: Relevant Literature, Arranged in Order of Contribution by Topic as Follows:

Business Continuity Planning (General) - Orange, Discrete-Event Simulation -

Purple, Risk-oriented Decision Support - Red, Risk Measurement- Green.

3.1: Model Flow

3.2: Example Multi Hazard Risk Frequency Distribution

3.3: Example Project Model, Simio Interface

3.4: Add-on Process Logic, Simio Interface

3.5: Post Discrete-Event Simulation Cost Analysis

3.6: Choice Model, Example Scatter Plot Representation of Choices

5.1: Testing for Model Accuracy

5.2: Formula for Net Savings 2

5.3: Formula for Net Savings 2 (Revised)

5.4: Case 1 Graphical Comparison of Optimal BCP Net Savings 56

5.5: Formula for Net Savings 3

60 


\section{Chapter 1 - INTRODUCTION}

Great loss in revenue can occur as a result of disruptive events in global supply chains (Sheffi, 2005, p. 13). Over the past two decades, as a result of this growing circumstance, companies and researchers have increased their focus on the potentiality of disruptive events, such as hurricanes, earthquakes and strikes, to disrupt a supply chain and response methods to such significant events (Samaddar, 2010, p. 88). Corporations, as well as various professional societies including the International Symposium on Logistics, have advancing interest in this issue. Whether manmade or natural, disruptive events threaten to disturb the flow of goods in

supply chains, halting production, sales and the loyalty of customers and investors. There is a new need for methods to tackle this issue.

The term "Business Continuity Plan," or "BCP," is increasingly used for the defining of a set of strategies developed by companies to maintain operations in the event of disruption to business flow, often specifically to supply chain operations (Ojha and Gokhale, 2009, p. 243). While the term 'BCP' has been defined in a variety of ways, it will be assumed here to include both mitigation plans (preventative actions) and contingency plans, when action is planned for before the event of a disruption. Business Continuity Planning refers to the development of an entire strategic process to address disruption risk; this paper will address a specific method that supports the process of BCP.

There is a need for established managerial solutions to supply chain disruptions, and while language for standard practices in Business Continuity Planning are still underdeveloped, an expanse of work has been begun to develop around this topic. Researchers, including Yossi Sheffi of MIT and others, have done considerable studies around the topic of BCP. 
After learning about a variety of methods and models and speaking with the Supply Chain Risk Management (SCRM) team at a major technology company in California, contribution to the body of knowledge about use of simulation in supporting BCP was sought by the author.

While some previous work addresses discrete-event simulation for managing supply chain disruption risk, few publications propose ways to integrate simulation into the BCP planning process. Therefore, the following question is proposed:

Can the use of risk index optimization add value to discrete-event simulation for decision support in Business Continuity Planning? How might this be done?

\section{General Approach}

This thesis will address the afore-stated question by proposing and testing a model that uses both discrete-event simulation and risk index assessment to address disruption risk in a supply chain network. Testing and results of case studies that implement the method developed will provide insight into the feasibility of such method, providing the modeling to do so.

Predicted savings according to the risk assessment method and the discrete-event simulation will be compared and differences in method results will be explained in detail to further assess the advantages and shortcomings of each method. Monte Carlo simulation will be employed to generate parameters for probabilistic distributions for risk frequency and impact. These distributions will then be input to a discrete-event simulation model developed in Simio software.

A combinatorial optimization model will be used to choose the best combination of responses, acting as a 'pre-screening' prior to testing in Simio (discrete-event simulation). A large number of combinations of responses to risk at various locations in the supply chain will be 
assessed according to how they compare to the others by losses mitigated and the cost of implementing that response combination. While the decision support model will provide optimal solutions from risk index and cost parameters, the simulation in Simio will provide a clearer understanding of the savings and cost changes under various response scenarios. Such a setup will model the presence of multiple suppliers and inventory levels because of the incorporation of stochasticity of disruption and production, providing the strongest prediction of the effectiveness of response plans.

In addition to literature on disruption simulation and testing of response plans, general supply chain risk management literature will play a role in the development of this model. Tummala and Schoenherr (2011, p. 220), discuss the need for a, "structured and systematic approach to enumerate supply chain risks," to assess their severity and likelihood and to look at the costs involved in "preventative actions." Similarly, the model developed in this thesis will consist of a method for risk assessment, being summarized as follows:

1. Enumeration of the disruption risks at each node (supplier site) and the formation of multi hazard risk distributions using Monte Carlo simulation.

2. Discrete-event simulation modeling of the supply chain network with accurate demand/production rates and inventory levels.

3. Enumeration of possible mitigation or contingency plans at each node and the listing of the change to probability of occurrence and impact at each site a response has been implemented; listing of cost parameters associated with implementing each type of response. 
4. Use of the BCP Choice Model and obtaining Net Savings under each possible combination of responses.

5. Input of the top response combinations from the BCP Choice Model to the Simio model for a more accurate and detailed assessment of the effectiveness of the response choice.

\section{Issues and Assumptions}

This thesis focuses specifically on addressing corporate losses due to unmet demand, that is, profit that would have been achieved if the disruptive event had not happened. Additional types of losses including damage to company property, loss in market share (Wai \& Wongsurawat, 2013), and loss in customer confidence will not be modeled here.

Disruption risks that will be taken into account will be limited to natural disasters, or those which occur as a result of a supplier's geographical location, excluding man-made disasters such as bankruptcy, strike, and political crisis. Thus, the estimation of risk in this model will be more optimistic than if it were to include man-made disasters. The model can, however, incorporate these types of risks if information on their likelihood and impact were available and analyzed.

Costs of implementing plans will also be based on best estimates for specific parameters, including holding cost per unit of inventory per day, cost of negotiations associated with sourcing, and the value of losing an established supplier relationship. Thus, some characteristics of a change in policy as well as the details relating to its cost will be rough informed estimates. For most effective use of this model, data input must come from thorough and accurate interviews with multiple members of the corporation in question. 


\section{Chapter 2 - LITERATURE REVIEW}

Companies who understand that financial loss is imminent develop methods of response to disruption, or Business Continuity Plans, to address risk in advanced and in the event of disruption. With the growing need for Business Continuity Planning in industry, there has been a growing trend in academic research in the past twenty years about this topic, continuing into the present.

This thesis looks specifically at the use of discrete-event simulation for decision support in Supply Chain BCP, an area where further research is needed. As pointed out by Manuj (2009), while mathematical modeling and simulation are widely used in Supply Chain Management, "research... does not satisfactorily address and/or report the efforts taken to maintain the rigor of simulation studies" (p. 173). A variety of work, described below, has been done, but user-friendly methods of implementing discrete-event simulation to support BCP need to be established. This chapter attempts to describe and evaluate the most influential research pertaining to the topic of established and approachable methods of discrete-event simulation to support BCP. Further, it explains the impact and motivation of said research to create the model that was established by the author here. 


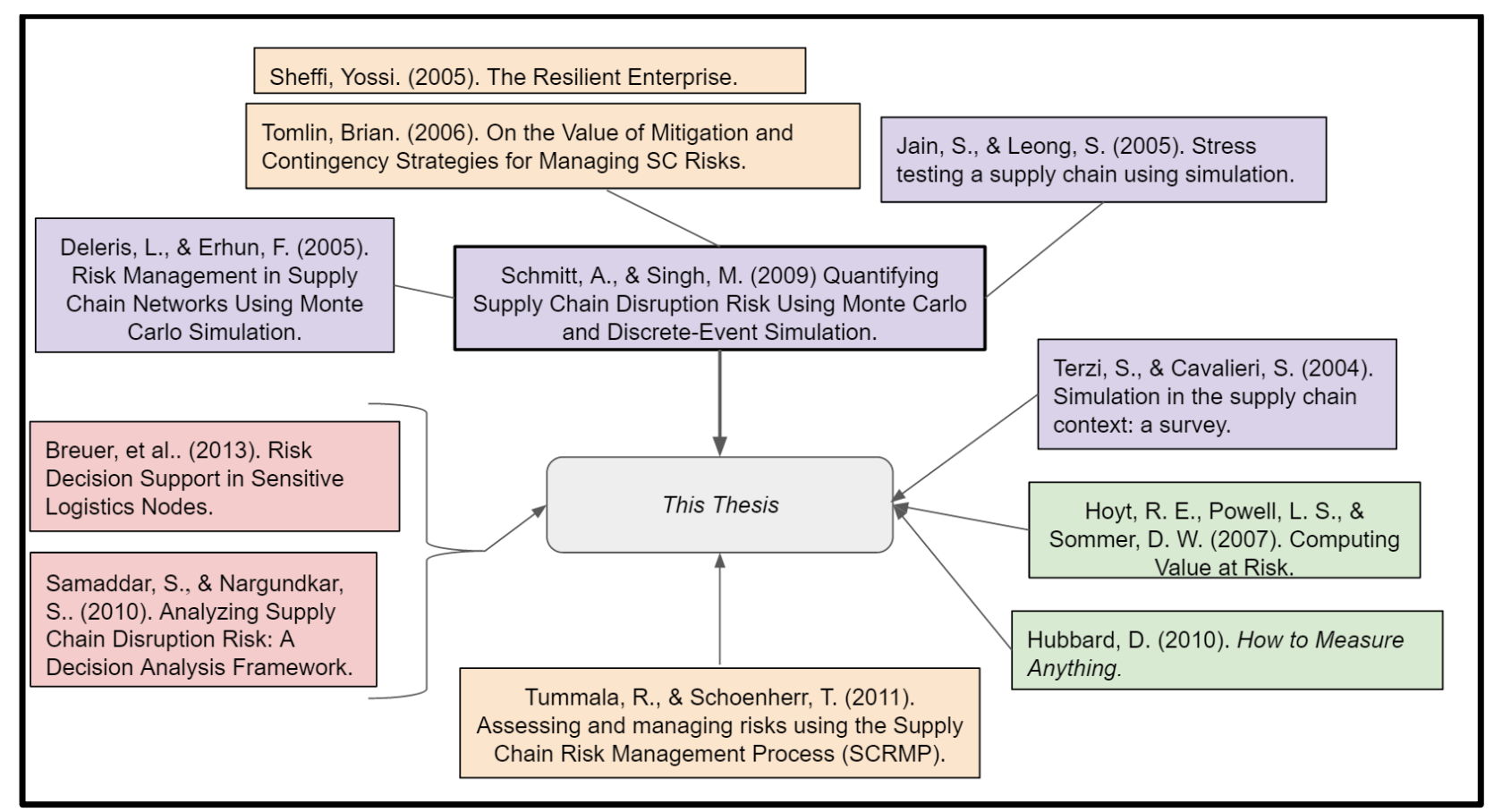

Figure 2.1: Relevant Literature, Arranged in Order of Contribution by Topic as Follows: Business Continuity Planning (General) - Orange, Discrete-Event Simulation - Purple, Risk-Oriented Decision Support - Red, Risk Measurement- Green.

Figure 2.1 depicts a color-coded map of various approaches to Supply Chain Risk Management and Business Continuity Planning. In particular, each of these most influential articles provided motivation for the development of the supply chain decision support simulation model.

\section{Business Continuity Planning (General)}

“Assessing and Managing Risks using the SCRMP," a paper by Tummala (2011) had a major impact on this thesis' methodology. It lists useful actions such as to, "enumerate supply chain risks and to assess their severity and likelihood," by providing a way to accurately model the enumerated risks' impact on the network and to determine the best set of responses while keeping financial implications in mind (2011, p. 475). Describing risk planning, it states that, "Since it is not feasible and practical to develop mitigation and prevention strategies for every risk 
identified, risk-planning begins with the examination of the costs required to implement each preventative action..." (2011, p. 482). The SCRMP (Supply Chain Risk Management Process) suggested in the paper provides a guide for evaluating and responding to disruption risk in Supply Chain. However, while various types of simulation methods are mentioned (p. 480), none are specifically demonstrated in the study, a vacancy for further work of useful risk planning methods combined with simulation methods in supply chain management.

Other fundamental SCRM concepts are found in Brian Tomlin's "On the Value of Mitigation and Contingency Strategies for Managing SC Risks" (2006). Tomlin proposes a comprehensive set of, "strategies for managing supply chain risks... inventory, reliable supplier, acceptance, mixed, contingent rerouting, demand management and business interruption insurance," (p. 639) from which the author's own set of response strategies were drawn. Tomlin proposes a mathematical model with which to analyze the above-stated response strategies (p. 642). This mathematical leg-work and response evaluation-centered approach is valuable for BCP simulation, and the work lends itself to the use of simulation models that can implement the evaluation methods established by Tomlin.

\section{Risk-Oriented Decision Support}

The analysis of response strategies to supply chain disruption risk, as carried out by Brian Tomlin provides a decision-support approach to BCP. In fact, a variety of recent literature focuses specifically on what is referred to as "Risk-oriented Decision Support" for BCP.

"Risk Decision Support in Sensitive Logistics Nodes," (2013)by Breuer, et al., along with Samaddar's “Analyzing Supply Chain Disruption Risk: A Decision Analysis Framework” (2010) were influential regarding decision support methods. Breuer, Castine, Siestrup, and Haasis (2013) 
provided a framework which in fact involves the use of both a discrete-event simulation model and decision trees for decision support. While the article by Breuer, et al. (2013) portrayed a paramount idea by combining these methods, the model focuses on disruption risks on a reactive case-by-case basis by, "building the base for testing the impacts of damaging events and for evaluating possible action strategies" (p. 218). Implementation of their proposed strategy is not included in their paper and would heighten its validity. Additionally, the methodology proposed by Breuer, et al. provides what is referred to as, "reactive risk management" (p. 218), whereas this thesis will evaluate multiple hazard risk response strategies as they are established prior to the event disruption, a proactive decision support model.

Samaddar and Nargundkar (2010) also suggest a, "Framework for strategic response to different levels of uncertainty," which involves the use of decision trees (p. 89). Again, while their approach is especially useful for decision support at the moment of supply chain disruption, the case-by-case planning method does not provide all that is needed for decision support in business continuity planning.

\section{Discrete-Event Simulation}

In addition to research into the combined approaches mentioned, research was done regarding methods of using discrete-event simulation for handling disruption risk in a supply chain. A survey of such efforts by Terzi and Cavalieri (2003) reviewed more than eighty papers, taking stock of the various published uses simulation for supply chain decision support arguing that among qualitative methods. "Simulation is undoubtedly one of the most powerful techniques to apply, as a decision support system, within a supply chain environment" (Terzi and Cavalieri, p. 4). Of the papers surveyed by Terzi and Cavalieri, a fourth of the single-processor supply chain 
simulations were performed using Arena software; however, none were documented as using Simio, which will be used here.

The authors note that the surveyed uses of simulation can be sorted into two types of paradigms- parallel integrated models or single models. They argue that parallel integrated models (with multiple processors) are more effective than single simulation models incorporating all location nodes in one model (Terzi and Cavalieri, 2003). This thesis tests only a single processor model to aid in supply chain decision support, due to its less complicated, more usable setup. However, future work which involves a multi-processor discrete-event simulation in combination with risk planning for BCP is suggested.

The discrete-event simulation portion of the project was inspired by a 2009 paper by Amanda Schmitt and Mahender Singh, published out of MIT, “Quantifying Supply Chain Disruption Risk Using Monte Carlo and Discrete-Event Simulation.” Schmitt and Singh use Arena for discrete-event simulations and @Risk for Monte Carlo simulations as a, "means to quantify" risk, model flexibility to variation, and test mitigation procedures, proving that, "risk is dynamic," and that a model must account for this (Schmitt and Singh, 2009, p. 1248).

This thesis builds on Schmitt and Singh's work by employing various technical solutions they used for modeling disruption risk and using these in discrete-event simulation as a part of a risk management process. At the same time not all techniques of Schmitt and Singh were used in order to create a convenient model that is less in-depth.

In further advancement, the functionality of Simio software is tested here, and various modifications and ideas for model setup are implemented because of the differences in software choice. 
Methods motivated by Schmitt and Singh's model include:

- Use of Monte Carlo simulation to generate 'multi hazard' risk disruption distributions modeled at supply chain nodes (supplier sites).

- Use of 'demand' object entities.

- Use of 'product' object entities.

As with Schmitt and Singh, further motivation was drawn from work by Jain \& Leong (2005) and Deleris \& Erhun (2005). Jain and Leong, who like others used Arena software to model disruptions in a supply chain, reiterate that, "Simulation provides the capability to evaluate performance of a system operating under current or proposed configurations, policies or procedures," (2005, p. 1650). What makes their model unique is that it is done from the position of Small and Medium Enterprises (SMEs), and the use of simulation modeling to reduce an Original Equipment Manufacturer's (OEM) perceived risk of sourcing from an SME” (p. 1650). While that perspective is useful for SMEs, this thesis looks to assist OEMs in running their own simulations.

"Risk Management in Supply Chain Networks Using Monte Carlo Simulation" (2005) by Deleris and Erhun as well as "Stress Testing a Supply Chain Using Simulation" (2005) by Jain and Leong provide multiple useful insights regarding the use of simulation in business continuity planning. Arena is used to model supply chain network flow as it behaves under demand surges. Similarly, the discrete-event simulation model developed in this thesis tests the behavior of the supply chain system under production shortages. 


\section{Risk Measurement}

Douglas Hubbard's “How to Measure Anything," (2010) provided confirmation that the technique of Monte Carlo simulation warranted application. Hubbard mentions in his chapter on Monte Carlo simulation that NASA uses, "soft risk score and more sophisticated Monte Carlo simulation to assess the risk of cost and schedule overruns and mission failures. The cost and schedule estimates from Monte Carlo, on average, have less than half the error of traditional accounting estimates" (p. 96). Hubbard reminds us that, "Using ranges to represent your uncertainty instead of unrealistically precise point values clearly has advantages," and that Monte Carlo simulation is, "a practical, proven solution (to adding, subtracting... in a spreadsheet when we have no exact values)" (p. 81). Additionally, Hubbard confirms the value of using simulation in risk mitigation, stating that, "If a risk is high enough,... an elaborate simulation could easily be justified to support our decision" (p. 99).

\section{Other Sources of Information}

Alongside methods for simulation and decision support drawn from various literature, sources of data regarding disruption risk were required. While a single global source for such data was not found, depending on geographical location, certain sources proved to be useful and more trustworthy than others, proving a need for a certain kind of publically available database regarding global disaster risks. In particular, the percent likelihood of an event (based on number

of occurrences over a certain number of years) and its average financial impact, listed directly and sorted according to the most impactful potential event, would be the most useful type of information for use in this simulation. The best source of information for global disruption risk data found came from PreventionWeb, an online database providing lists of top disasters by 
country, according to frequency, mortality, and "Hazard Contribution to AAL (Average Annual Loss)." PreventionWeb, “a project of the United Nations International Strategy for Disaster Reduction Secretariat," although collaborative, is a strong source of information (“PreventionWeb.net FAQ," 2014); however, disaster risk maps are not up to date for all country profiles, and thus, it is hard to find up to date information for specific cities and regions within a given country. (Japan Hazard Map, 2007).

In summary, the literature reviewed reveals that a number of methods and resources for decision support in response to supply chain disruption risk exist. Among those methods, discreteevent simulation is used to observe disruption scenarios, response to the disruption, and the overall impact on the performance of the system. Studies which incorporate combinations of discrete-event simulation with other decision support methods do so a case-by-case manner, through the use of tools that are effective reactively. However, none of the literature reviewed looks specifically at the combined use of risk decision support and discrete-event simulation in choosing the best set of response strategies to multiple risks prior to an event. Literature which includes the use of discrete-event simulation does not employ Simio software, and this is an area in itself worth exploration. This thesis seeks to provide a method for BCP decision support that integrates discrete-event simulation in Simio into a disruption risk planning process. 


\section{Chapter 3 - SYSTEM DESIGN}

In order to assist companies in planning for the best responses to multiple risks of disruption, a decision support method that integrates discrete-event simulation was developed. The process starts with a simulation of a supply chain network and its vulnerabilities, or "Vulnerability Simulation" (Figure 3.1) followed by Monte Carlo simulation which develops combined node risk parameters. These parameters, along with other information about the supply chain are put into the discrete-event simulation model in Simio. Response options are tested (Figure 3.1) by running an optimization in Microsoft Excel, a knapsack problem, that, using Risk Index (probability of disruption x cost of disruption) under various scenarios as a coefficient, chooses response combinations that result in the greatest monetary savings. After potential optimal response choices are pinpointed, discrete-event simulation in Simio is used for a detailed analysis of expense reduction under pre-response and post-response scenarios. Results reported from the simulation scenarios, including unmet demand and average inventory held, provide a graphical comparison that can be used for executive decision support. 


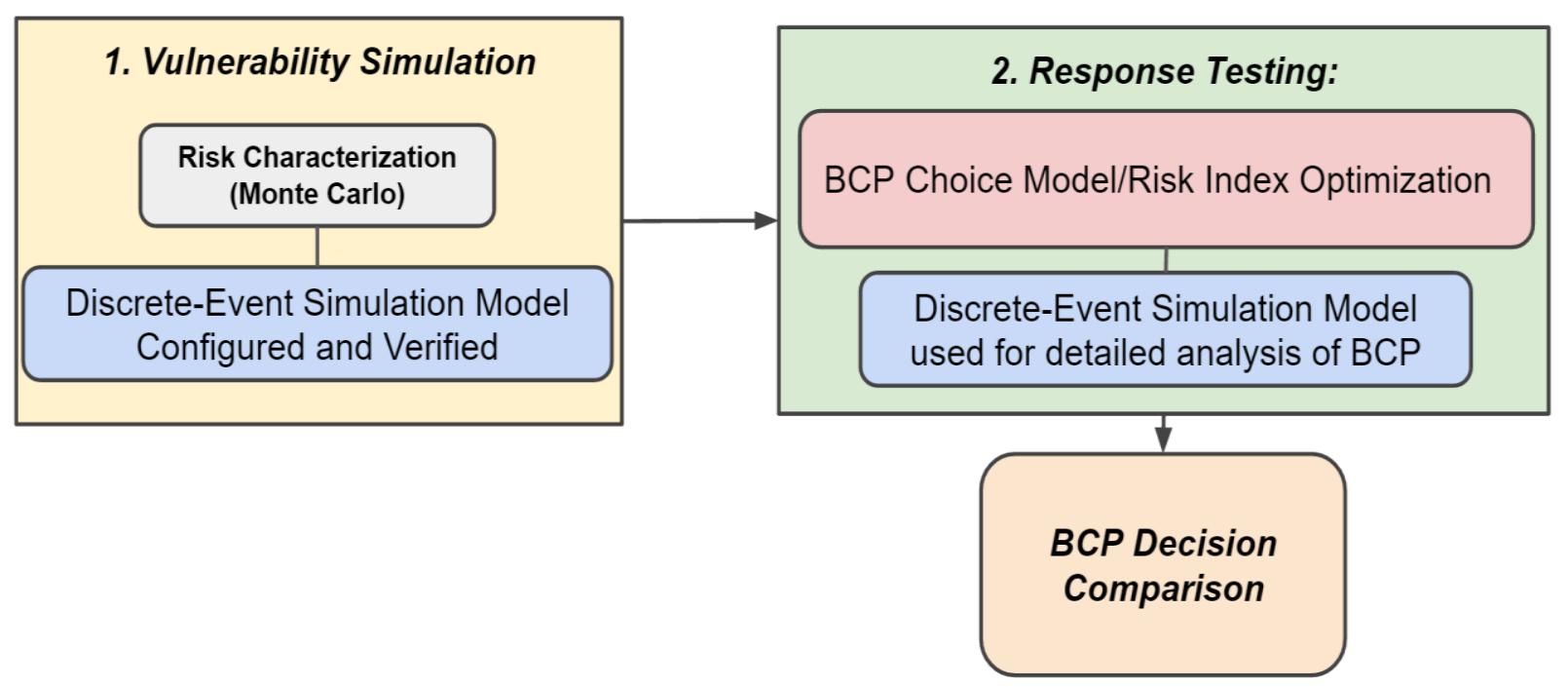

Figure 3.1: Model Flow

In short, the process to be described can be summarized as follows:

Part 1: Vulnerability Simulation

1. Enumeration of the disruption risks at each node, or supplier site, and the formation of multi hazard risk distributions using Monte Carlo simulation.

2. Discrete-event simulation modeling the supply chain network with accurate demand/production rates and inventory levels.

Part 2: Response Testing

3. Enumeration of potential mitigation or contingency plans at each node (supplier site) and the listing of the change to probability of occurrence and impact at each site a response has been implemented; listing of the cost parameters associated with each type of response.

4. Use of the BCP Choice Model and obtaining Net Savings under each possible response combination. 
5. Input of the top response combinations from the BCP Choice model to the Simio model for an accurate and detailed assessment of the effectiveness of the response choice.

It is the author's intention that the setup of this process, in addition to its implementation and testing (Chapters 4 and 5), will provide a concept that is both well-informed by previous methods and models and still approachable for any researcher or executive responsible for managing disruption risks in a global supply chain network.

\section{Node Risk Profiles and Monte Carlo Simulation}

In order to respond to risks in a supply chain, we must understand the nature of the risk. Thus, the initial simulation, modeling the supply chain's vulnerability, takes into account the likelihood of a disruptive event and its magnitude. Use of these important factors can be found throughout risk management literature.

Multiple events must be taken into consideration, and thus measuring such risk becomes more complex. Use of Monte Carlo simulation, therefore, was prescribed, in line with Schmitt and Singh (2009) to generate probabilistic distributions to represent the risks of any disruptive event (p. 1243). These distributions are useful for input to a discrete-event simulation because the servers in the simulation will read single probabilistic distributions for the interarrival time of disruptive events (i.e. failures) and number of days down.

The Monte Carlo simulation can create an intersecting probabilistic distribution, that is, a distribution which combines multiple elements which themselves have an estimated likelihood. Monte Carlo also provides a way to express uncertain knowledge more accurately. "Most of us are systematically overconfident and will tend to underestimate risks unless we avail ourselves of 
the training that can offset such effects." "Monte Carlo uses a brute-force approach to randomly pick a bunch of exact values ... according to the ranges we prescribe...the probabilities of different results can be estimated" (Hubbard, p. 80-84).

Monte Carlo simulation was run in Excel to develop Node Risk Profiles and beginning with an enumeration of the most likely and/or impactful disruptive events at a given site. (Table 3.1) Based on historical data, each type of disruptive event can then be assigned an estimated probability of occurrence, which then is converted to a probabilistic, exponential expression of interarrival time between disruptions.

Schmitt and Singh (2009) assert that the exponential and triangular distributions best represent the interarrival time of disruptive events to a plant and the days a plant will be down, respectively. Thus, both exponential and triangular distributions are employed in this study, both for individual types of disruptions and for the multi hazard risk distributions (p. 1243).

\begin{tabular}{|c|c|c|c|}
\hline Event & Source of Information & Probability & $\begin{array}{l}\text { Average Days between } \\
\text { Occurrences }\end{array}$ \\
\hline $\begin{array}{l}\text { Earthquake and } \\
\text { Tsunami }\end{array}$ & Earthquake intensity zone & $0.00410959 \%$ & 24333.33333 \\
\hline \begin{tabular}{|l|l|} 
Storm Surge (due to \\
2 Typhoon or cyclone) \\
\end{tabular} & & & NA \\
\hline 3 Flood (river and flash) & $\begin{array}{l}\text { "Floods.Pop.Exp:: } \\
\text { “Dynamic" } \\
\text { PreventionWeb map }\end{array}$ & $0.01883562 \%$ & 5309.090909 \\
\hline 4 Landslide & $\begin{array}{l}1000 \text { people affected } \\
\text { per year }\end{array}$ & $0 \%$ & NA \\
\hline 5 Volcano & 25153.79222 & 0 & NA \\
\hline & & & AVE(AVE) \\
\hline Exponential & & $0.0314266 \%$ & 3182.018344 \\
\hline
\end{tabular}

Table 3.1: Example Risk Profile with Monte Carlo Simulation

Using the exponential distributions for each potential event, the Monte Carlo simulation creates a combination of these distributions, a single probabilistic distribution. This distribution is 
generated through the use of the RAND(x) function in Excel for the value of $x$, the numbered event, in the inverse exponential distribution for each event type (Table 3.2). Ten thousand scenarios are then generated and the resulting sum of probabilities are tallied, forming a distribution of outcomes, shown by the bar graph (Figure 3.2).

\begin{tabular}{|c|c|c|c|c|}
\hline Scenario & Earthquake and Tsunami & $\mathrm{P}$ & Flood (river and flash) & $\mathrm{P}$ \\
\hline \multicolumn{2}{|c|}{$1=-\operatorname{LN}(1-\operatorname{RAND}()) * \mathrm{~F} \$ 4$} & $=1 / \mathrm{B} 16$ & $=-\mathrm{LN}(1-\mathrm{RAND}()) * \$ \mathrm{~F} \$ 6$ & $=1 / \mathrm{D} 16$ \\
\hline 2 & 22021.03003 & $5 E-05$ & 29353.50804 & $3.407 \mathrm{E}-05$ \\
\hline 3 & 114.8832357 & 0.0087 & 2008.570733 & 0.0004979 \\
\hline & & n nmm & & \\
\hline
\end{tabular}

\begin{tabular}{|r|r|}
\hline Intersecting Time between arrivals & Combined Probability \\
\hline =1/K16 & $=S U M(C 16, \mathrm{E} 16, \mathrm{G} 16, \mathrm{I} 16)$ \\
\hline 12582.00086 & $7.94786 \mathrm{E}-05$ \\
108.6678159 & 0.009202357 \\
262561152 & n nnnsonoc2
\end{tabular}

Table 3.2: Example Monte Carlo simulation scenarios (3 of 1000)

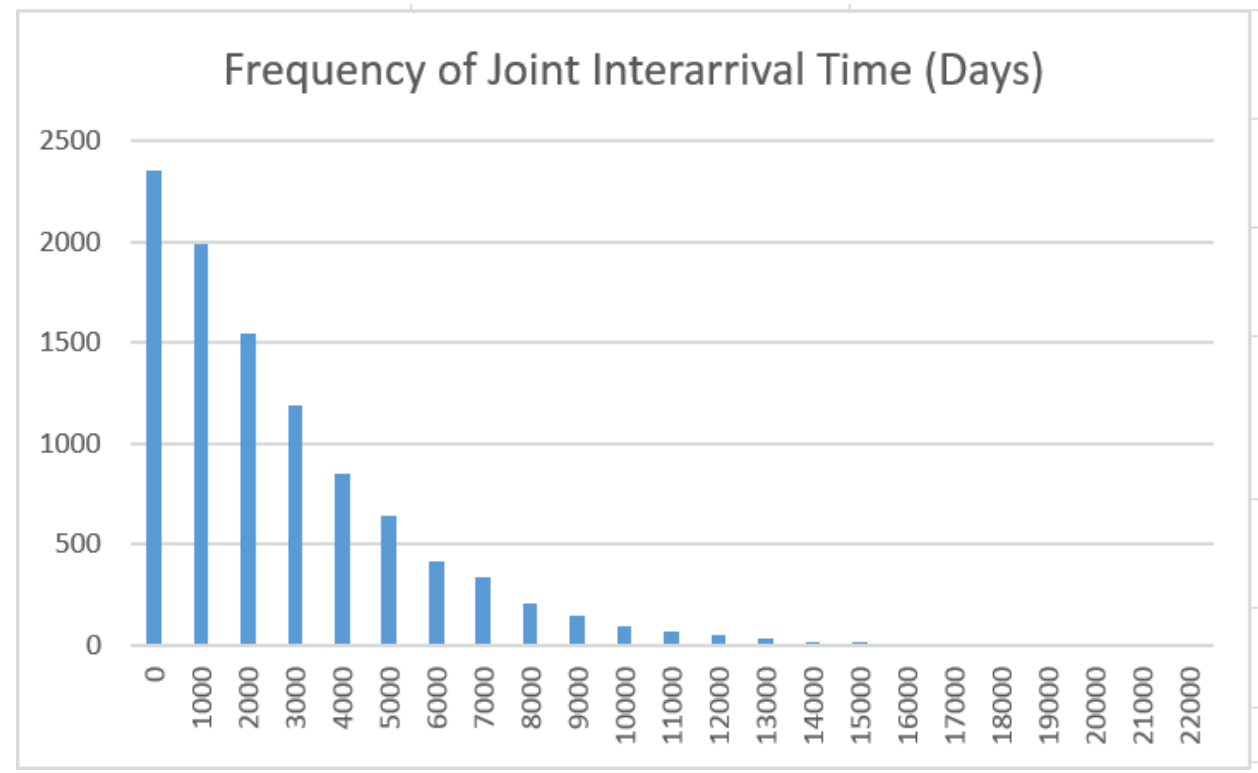

Figure 3.2: Example Multi Hazard Risk Frequency Distribution

The Monte Carlo simulation procedure described above is also employed to generate a distribution for the average number of days a supplier will not be able to run due to any given 
disruption. As mentioned, the triangular distribution lends itself well to estimating the number of days a plant will be down due to the ability a supply chain professional to state the minimum, maximum, and estimated median number of days a plant will not be in operation if a certain type of disruption were to occur (Schmitt \& Singh, 2009, p. 1243). Just as with the Monte Carlo simulation for generating a distribution for disruption interarrival times, ten thousand replications of a set of three randomly generated outcomes of specific triangular distributions create a single distribution for the minimum, mode and maximum number of days a site will be down if a disruption of any of the listed types occurs.

\section{Discrete-Event Simulation: System Design}

After being generated through Monte Carlo simulation, probabilistic distributions for disruption interarrival times and days down are then be used in the discrete-event simulation model. As opposed to creating generated disruption 'entities' (as in Schmitt and Singh, 2009), this model uses the functionality in Simio of server Reliability Logic. The Reliability Logic, traditionally used to represent machine failures on a manufacturing floor, specifies "Uptime between failures" and "Time to repair." Although in this model servers are used to represent nodes (supplier sites) in a supply chain, the functionality can still be adopted to represent supply chain disruptions because Uptime between failures is used in the same way as time between failures. While future work could be done to compensate for variation due to this difference in this logic, this paper assumes that any differences are small, and the Reliability Logic in Simio is used as is. 
Simio allows for the modeling of a set of multiple nodes (supplier sites) with various risk profiles, and distributions are specified in a window for the respective server (Table 3.3). Setup of reliability logic for servers will go on to impact the results of the simulation model.

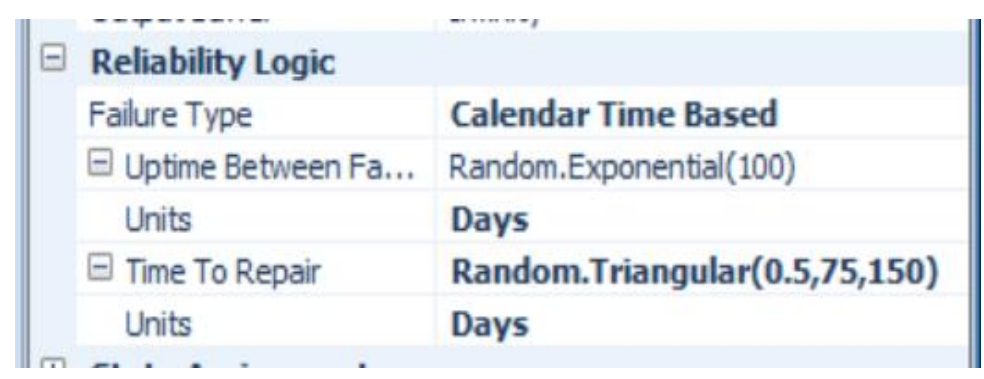

Table 3.3: Example Server Reliability Logic Settings, Simio Interface

Continuing the discrete-event simulation model setup, "Order," or demand entities, and product entities are defined and depicted as green triangles in the system. The model goes on to depict virtual supply chain nodes (supplier sites) with respective sources of material through source objects. Lines between sources, servers, combiners, and sinks are Connectors rather than Paths, resulting in instantaneous travel between nodes, as this simulation does not take travel time into account.

A final Combiner object (Figure 3.3) is an import piece of the model setup, matching Product entities with Order demand entities in a 1:1 ratio. Ultimately, the output of the combiner, a single object, is fed to the "Sales" sink, modeling a fulfilled customer order. Unmet Demand is measured when Order entities go into the sink Unmet Demand sink, which occurs when no product is waiting at the Parent Input Buffer, or inventory, at "Combiner1." 


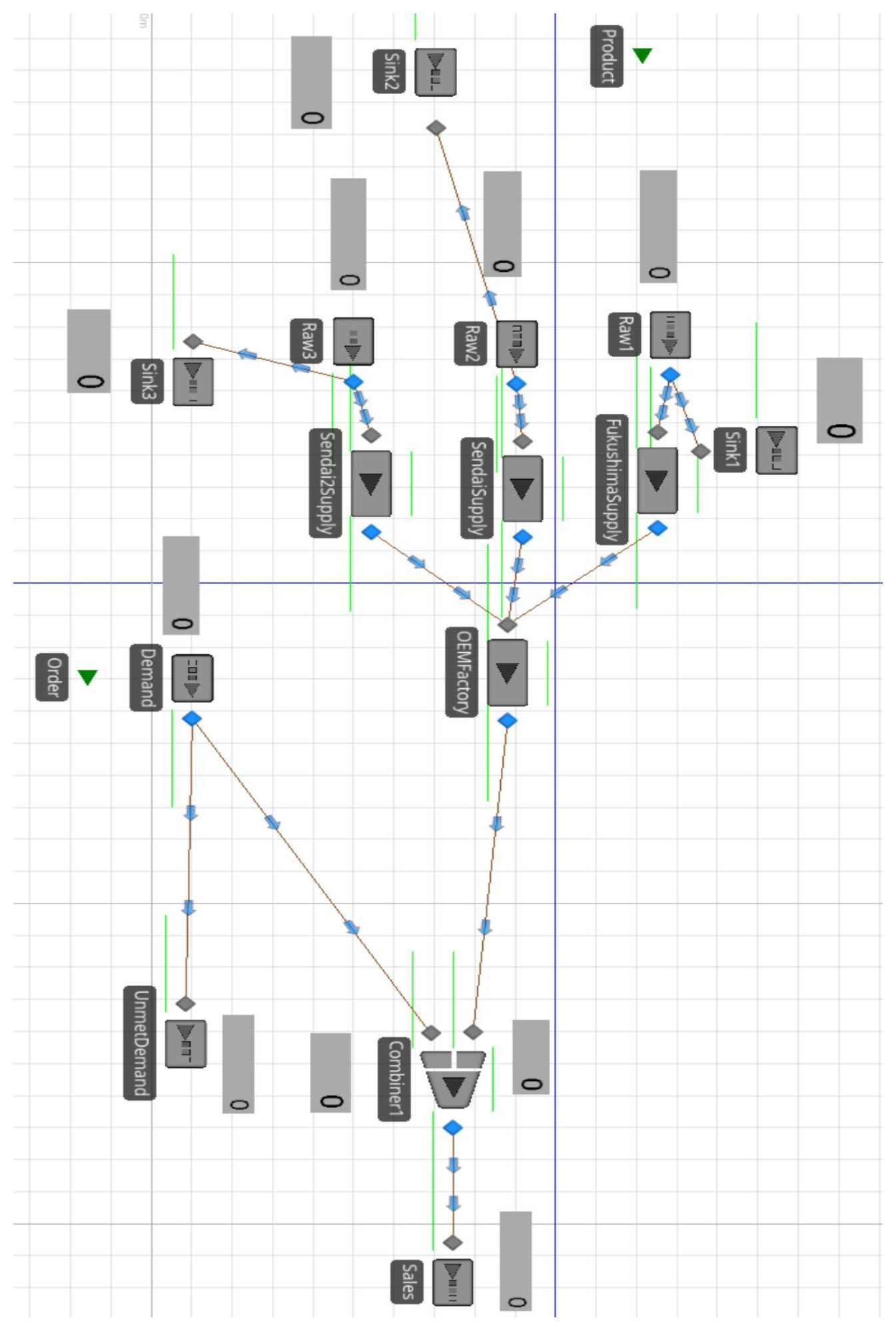

Figure 3.3: Example Project Facility Model, Simio Interface 
Status Labels are included at various points in the model in order inform the user the behavior of the simulation model in test runs. (Figure 3.3) Add-on processes were created (Figure $3.4 \&$ Table 3.4) to direct item entities to not accumulate at the supplier when it is down. This was done to more realistically model what might happen if a disruption were to occur. Third-tier suppliers of material would not have infinite inventory capacity and the second-tier suppliers would not have the capacity to purchase the backed-up surge in materials after the disruption ends. Thus, accuracy is maintained in the model.

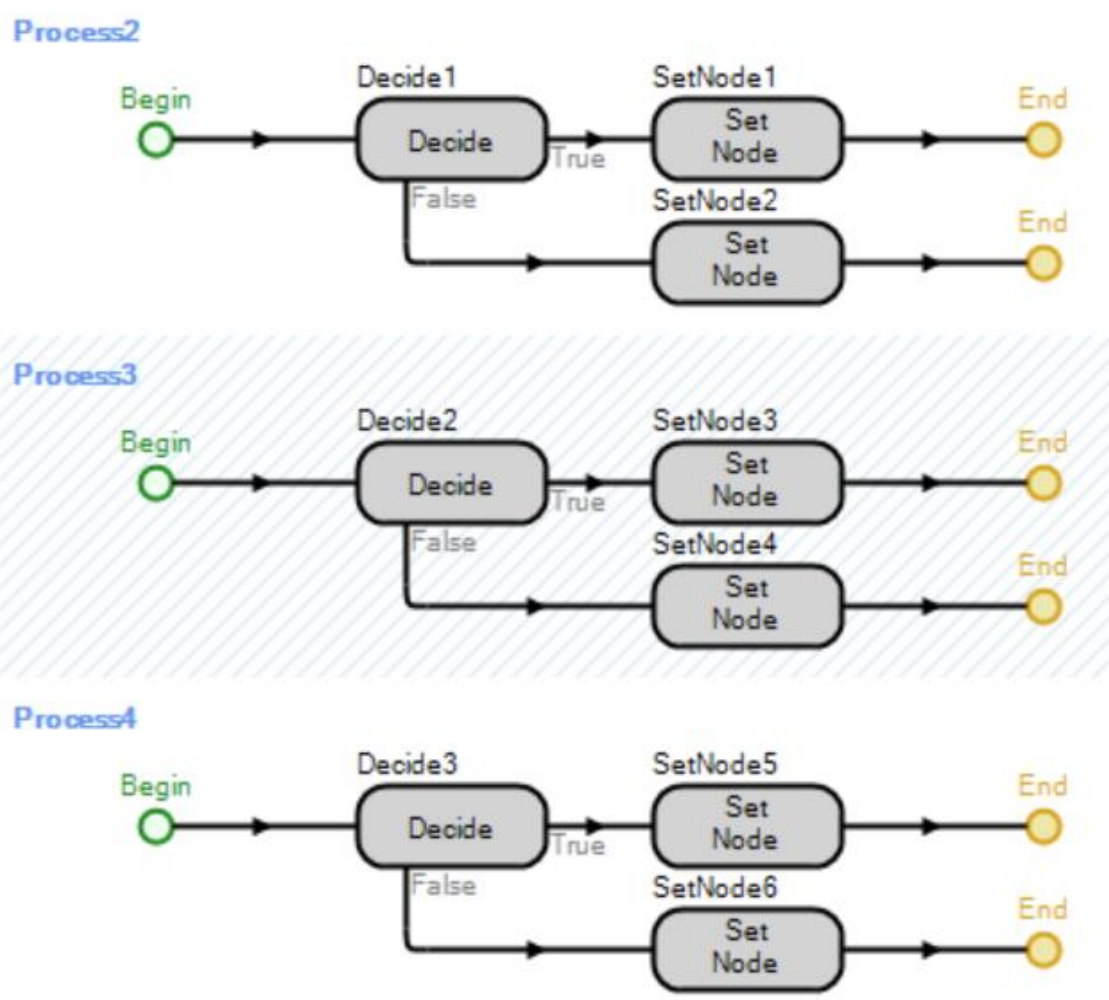

Figure 3.4: Add-On Process Logic, Simio Interface 


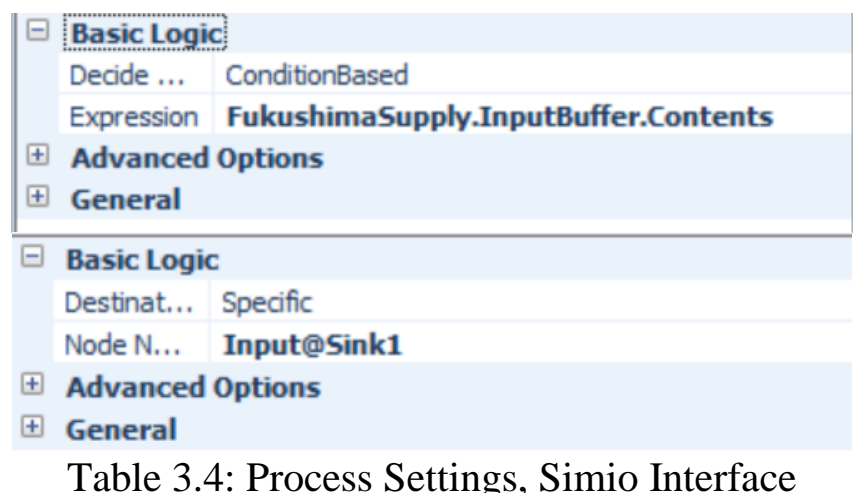

The model was set to run over the course of 365 simulated days plus the amount of days inventory in policy to be held at the OEM server. For instance a simulation run over the course of a year may be programmed at 341 days, to account for a delay in the production of demand entities by five days in order to build an inventory at the OEM server of five days production. Once the model is created as described above, the testing ultimately provides insights into the expected performance of such a supply chain setup.

Part 2 Response Testing: BCP Choice Model-Combinatorial Risk Optimization The BCP Choice Model for decision support for response choices involves the following.

- Optimization of all possible responses through risk index method.

- Input of 'best' BCPs found in Step 1 to the Simio Vulnerability Model.

- Comparison of projected savings to projected cost.

The initial combinatorial optimization enumerates and compares all possible BCPs, a brute force to ensure that no combination of responses is overlooked. This initial optimization alone, however, does not provide the same amount of precision in estimating the risk associated with a given BCP. Thus, the discrete-event simulation goes on to more accurately predict the losses associated with initial, less precise 'gleaned' plans. 
A cost analysis is required, done with an Excel spreadsheet that allows for the input of various cost parameters. This cost calculator is flexible to change in its parameters and equations. Accurate modeling of costs associated with responses is crucial for the successful evaluation of BCPs in any real application.

The combinatorial risk index optimization model specifically operates by first listing all response/node combinations, through input of changed risk probabilities and days down for each node/response combination and input of parameters into cost model to project costs of BCPs through each node/response combination. Finally, calculation of net savings under all response combinations is performed.

\begin{tabular}{|c|c|c|c|c|c|}
\hline & \multicolumn{5}{|c|}{ Response $(\mathrm{Y} / \mathrm{N})$} \\
\hline Supplier & Reassign & $\begin{array}{l}\text { Assist with } \\
\text { Resilience }\end{array}$ & $\begin{array}{l}\text { Hold Extra } \\
\text { Inventory }\end{array}$ & $\begin{array}{l}\text { Second } \\
\text { Source }\end{array}$ & $\begin{array}{l}\text { Assist } \\
\text { Supplier } \\
\text { with } \\
\text { Recovery } \\
\end{array}$ \\
\hline $\mathrm{A}$ & & & & & \\
\hline B & & & & & \\
\hline & & & & & \\
\hline
\end{tabular}

Table 3.5: Decision Matrix, BCP Choice Model

The spreadsheet for calculating the values which we desire to optimize is shown above. A matrix (Table 3.5) on the spreadsheet indicates the combination of "Yes" and "No" to indicate whether or not a plan would implemented at a given node.

Below the decision matrix, the BCP Choice Model spreadsheet (Table 3.6) includes columns for the following: Node, Risk, and Risk Index (PxC) for each node prior to response; then, response chosen (as indicated in the Decision Matrix), corresponding risk parameters and indices, most optimal risk parameters of the ones indicated for inclusion, multi hazard risk parameters and indices at each node after response implementation (generated through Monte 
Carlo sheets), savings at the node (difference between Pre and Post-response risk indices), total savings and cost (pulled from the cost sheet).

The optimization model, which includes changes in risk parameters under the input of each response combination, chooses the lowest (risk x impact) combination (risk index) associated with each response or nonresponse. The lowest probability of occurrence in the probabilities listed for a given event at a node is pulled, as well as the smallest number of days down. This is based on the assumption that the most effective response results will define the new frequency of disruption and days down for an event at a given supplier site.

If the parameters pulled are generated by the response choice to second-source, the 'frequency' and 'days down' associated with the response that has the lowest risk index is chosen to represent the 'new' parameters under the given $\mathrm{BCP}$, or response combination, in tandem. Finally, these changes in Risk Indices are summed to come up with a value for the overall change (ideally, reduction) of risk at all nodes in the supply network, expressed as a dollar value for savings (Table 3.6). 


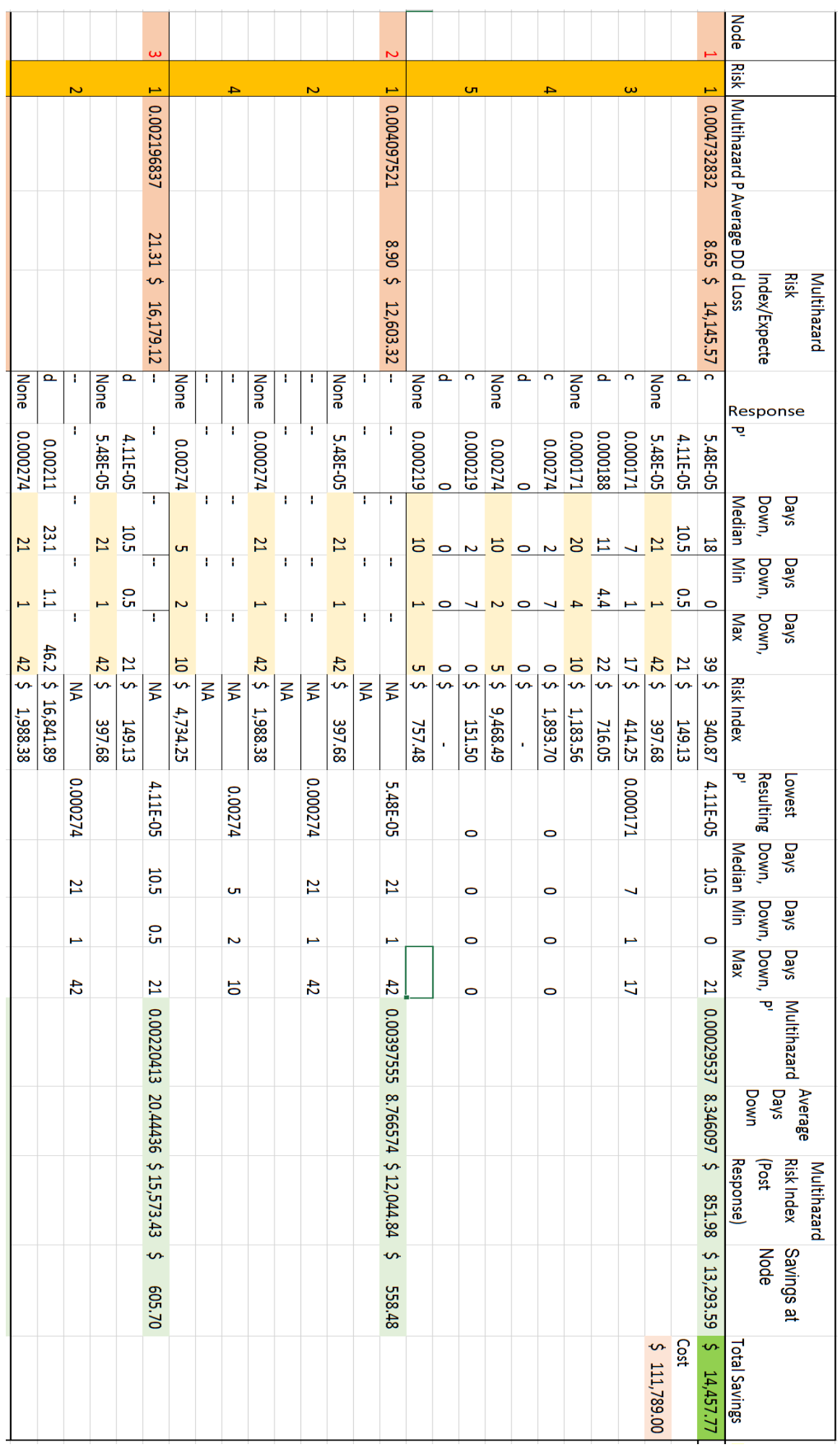

Table 3.6: Example BCP Choice Model 


\begin{tabular}{|c|c|c|c|c|c|c|c|c|c|c|c|c|}
\hline \multirow[b]{2}{*}{ Supplier } & \multirow[b]{2}{*}{ Risk } & \multirow[b]{2}{*}{ Probability Before } & \multicolumn{3}{|c|}{ Days Down Before } & \multirow[b]{2}{*}{ Response } & & & \multicolumn{4}{|c|}{ Post-Response Days Down } \\
\hline & & & Mediar & & Max & & \multicolumn{2}{|c|}{ Probability Post-Response } & Change & Mediar & Min & Max \\
\hline \multirow[t]{8}{*}{ Fukushima } & 1 & 5.47945E-05 & 21 & 1 & 42 & c & Same & $5.47945 \mathrm{E}-05$ & -3 & 18 & 0 & 39 \\
\hline & 3 & 0.000171233 & 10 & 4 & 20 & & Same & 0.000171233 & -3 & 7 & 1 & 17 \\
\hline & 4 & 0.002739726 & 5 & 10 & 2 & & Same & 0.002739726 & -3 & 2 & 7 & 0 \\
\hline & 5 & 0.000219178 & 5 & 10 & 1 & & Same & 0.000219178 & -3 & 2 & 7 & 0 \\
\hline & 1 & & & & & $d$ & \begin{tabular}{|r|}
$75 \%$ \\
\end{tabular} & 4.10959E-05 & $50 \%$ & 10.5 & 0.5 & 21 \\
\hline & 3 & & & & & & $110 \%$ & 0.000188356 & $110 \%$ & 11 & 4.4 & 22 \\
\hline & 4 & & & & & & $0 \%$ & 0 & $0 \%$ & 0 & 0 & 0 \\
\hline & 5 & & & & & & $0 \%$ & 0 & $0 \%$ & 0 & 0 & 0 \\
\hline \multirow[t]{6}{*}{ Sendai1 } & 1 & \#DIV/0! & \#REF! & & & c & \begin{tabular}{|l|l} 
Same \\
\end{tabular} & $5.47945 \mathrm{E}-05$ & 0 & \#REF! & & \\
\hline & 2 & \#DIV/0! & \#REF! & & & & Same & 0.000171233 & 0 & \#REF! & & \\
\hline & 3 & \#DIV/0! & \#REF! & & & & Same & 0.002739726 & 0 & \#REF! & & \\
\hline & 1 & & & & & d & \begin{tabular}{|r|}
$75 \%$ \\
\end{tabular} & $4.10959 \mathrm{E}-05$ & $50 \%$ & 10.5 & & \\
\hline & 2 & & & & & & $110 \%$ & \#DIV/0! & $110 \%$ & 11 & & \\
\hline & 3 & & & & & & $0 \%$ & \#DIV/O! & $0 \%$ & 0 & & \\
\hline \multirow[t]{4}{*}{ Sendai2 } & 1 & \#DIV/0! & \#REF! & & & c & Same & $5.47945 \mathrm{E}-05$ & 0 & \#REF! & & \\
\hline & 2 & \#DIV/O! & \#REF! & & & & Same & 0.000171233 & 0 & \#REF! & & \\
\hline & 1 & & & & & $d$ & $75 \%$ & $4.10959 \mathrm{E}-05$ & $50 \%$ & 10.5 & & \\
\hline & 2 & & & & & & $110 \%$ & \#DIV/0! & $110 \%$ & 11 & & \\
\hline
\end{tabular}

Table 3.7: BCP Response Impact, Example User Input

The optimization of BCP response combinations is achieved by pulling the values for 'Savings' and 'Cost' generated in the BCP Choice Model spreadsheet for each Yes/No combination into a spreadsheet listing all possible response combinations. 'Post-response' values mentioned in the BCP Choice Model spreadsheet (Table 3.6) were pulled from a 'Response Sensitivity' worksheet (Table 3.7), in which the user inputs percentage and/or integer values into the yellow highlighted columns. The cost of implementing the given BCP response combination is pulled from the 'Costing' spreadsheet. User input, highlighted in yellow in the cost worksheet (Table 3.8), are for parameters relating to costs of response plans. The formulas generating the costs related to implementing a given response at a supplier node are described in this table. Note 
that the user, if he/she wishes, can manually input a total cost for a supplier/response combination if the formulas do not generate the desired value.

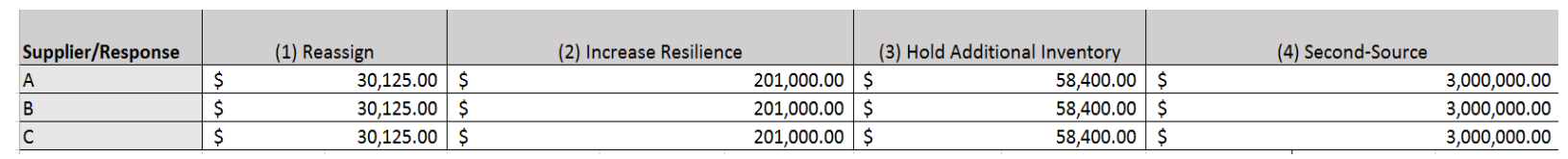

Table 3.8: Response Cost Parameters, Example User Input

Finally, the rows of this sheet are sorted according to the highest net savings (savings cost) under each response combination. (Table 3.9)

\begin{tabular}{|c|c|c|c|c|c|c|c|c|c|c|c|c|}
\hline Rank & ВCP & Sav & & Cost & Net Savings & $\begin{array}{l}\text { Node1 } \\
\text { /Respo } \\
\text { nseC }\end{array}$ & $\begin{array}{l}\text { Node1 } \\
\text { /Respo } \\
\text { nseD }\end{array}$ & $\begin{array}{l}\text { Node2 } \\
\text { /Respo } \\
\text { nseC }\end{array}$ & $\begin{array}{l}\text { Node2 } \\
\text { /Respo } \\
\text { nseD }\end{array}$ & $\begin{array}{l}\text { Node3 } \\
\text { /Respo } \\
\text { nseC }\end{array}$ & $\begin{array}{l}\text { Node3 } \\
\text { /Respo } \\
\text { nseD }\end{array}$ & $\begin{array}{l}\text { OME } \\
\text { Inventory } \\
\text { Change }\end{array}$ \\
\hline 1 & 127 & $\$$ & $(7,260.257)$ & $\$(691,200.00)$ & $\$ 683,939.74$ & $\mathrm{~N}$ & $\mathrm{~N}$ & $\mathrm{~N}$ & $\mathrm{~N}$ & $\mathrm{~N}$ & $\mathrm{~N}$ & $\mathrm{Y}$ \\
\hline 2 & 125 & $\$$ & $(2,331.066)$ & $\$(684,609.49)$ & $\$ 682,278.42$ & $\mathrm{~N}$ & $\mathrm{~N}$ & $\mathrm{~N}$ & $\mathrm{~N}$ & $\mathrm{~N}$ & $\mathrm{Y}$ & $\mathrm{N}$ \\
\hline 3 & 96 & $\$$ & $2,413.492$ & $\$(677,001.51)$ & $\$ 679,415.00$ & $\mathrm{~N}$ & $\mathrm{Y}$ & $\mathrm{N}$ & $\mathrm{N}$ & $\mathrm{N}$ & $\mathrm{N}$ & $Y$ \\
\hline 4 & 88 & $\$$ & $14,309.251$ & $\$(664,708.94)$ & $\$ 679,018.19$ & $\mathrm{~N}$ & $\mathrm{Y}$ & $\mathrm{N}$ & $\mathrm{Y}$ & $\mathrm{N}$ & $\mathrm{N}$ & $Y$ \\
\hline 5 & 94 & $\$$ & $4,886.542$ & $\$(670,411.00)$ & $\$ 675,297.54$ & $\mathrm{~N}$ & Y & $\mathrm{N}$ & $\mathrm{N}$ & $\mathrm{N}$ & Y & $\mathrm{Y}$ \\
\hline 6 & 86 & $\$$ & $16,158.221$ & $\$(658,118.43)$ & $\$ 674,276.65$ & $\mathrm{~N}$ & $\mathrm{Y}$ & $\mathrm{N}$ & $Y$ & $\mathrm{~N}$ & $Y$ & $Y$ \\
\hline 7 & 119 & $\$$ & $(5,312.922)$ & $\$(678,907.44)$ & $\$ 673,594.52$ & $N$ & $N$ & $\mathrm{~N}$ & $\mathrm{Y}$ & $N$ & $N$ & $\mathrm{Y}$ \\
\hline 8 & 117 & $\$$ & $(1,910.286)$ & $\$(672,316.93)$ & $\$ 670,406.64$ & $\mathrm{~N}$ & $\mathrm{~N}$ & $\mathrm{~N}$ & $Y$ & $\mathrm{~N}$ & $Y$ & $Y$ \\
\hline 9 & 111 & $\$$ & $7,768.431$ & $\$(460,800.00)$ & $\$ 468,568.43$ & $\mathrm{~N}$ & $\mathrm{~N}$ & Y & $\mathrm{N}$ & $\mathrm{N}$ & $\mathrm{N}$ & Y \\
\hline
\end{tabular}

Table 3.9: Example Top Choices, Sorted Decision List in BCP Choice Model

\section{Response Testing in Simio}

As mentioned previously, the BCP Choice Model described above provides a rough cut of the theoretically most cost-effective BCP response combinations. However, as research shows, discrete-event simulation provides the most accurate portrayal of the performance of a complex supply chain. Therefore, the next step in the process is to test the response choices in the Simio model developed in Part 1.

In order to prepare the model for testing of different cases, Experiments are created in Simio. The Experiment table in Simio (Table 3.10) was employed as follows. Rows in the 
Experiment table, each corresponding to a Scenario, were labeled for each BCP response case. To the right of the indicated scenarios is information about Replications. In this model, ten replications were specified, corresponding to ten different runs under the same scenario. Desired Responses, or measured outputs, were chosen to show the desired key performance indicators (KPIs), Production Loss, Unmet Demand, Average Inventory, and Sales. Unmet Demand and Production Loss indicated are the most important measurements for evaluation of Business Continuity Plans.

\begin{tabular}{|l|l|r|l|l|l|l|}
\hline \multicolumn{2}{|l|}{ Scenario } & Replications & Responses & & \multicolumn{2}{l|}{} \\
\hline$\square$ & Name & Completed & UnmetDemand & AverageInventory & ProductionLost & PotentialProd \\
\hline$\square$ Combo 128 & 10 of 10 & 0 & 15654.1 & 7910.6 & 224406 \\
\hline$\square$ Combo 127 & 10 of 10 & 0 & 14776.1 & 7213.6 & 224413 \\
\hline$\square$ Combo 95 & 10 of 10 & 0 & 17046.2 & 6490.7 & 224405 \\
\hline$\square$ Combo 125 & 10 of 10 & 0 & 13829.3 & 7672 & 222740 \\
\hline$\square$ Combo 126 & 10 of 10 & 0 & 15597.6 & 7231.4 & 224376 \\
\hline$\square$ Combo 93 & 10 of 10 & 0 & 16212.4 & 6143.8 & 224356 \\
\hline
\end{tabular}

Table 3.10: Example Response Scenarios, Simio Interface

Ten replications were run for each scenario in the experiment in order to come up with the most accurate results. Each scenario involves changing the risk parameters programmed in the servers and changes to the size of the inventory buffers at servers, if the BCP indicated such a change. Alternatively to experimental runs, the virtual model of the supply chain network and its Status Labels serve as a means for the user to test the behavior of the simulation under a variety of model configurations and also to test that the model is functioning as desired.

\section{Part 2 Simulation Result Analysis}

Management is best served by several options that can be compared to one another. 
From the experimental scenario runs, the desired KPI outputs, unmet demand, average inventory, sales, and production loss recorded are analyzed and interpreted. Conversion of experiment results to dollar values are as follows. Net savings (Figure 3.5) was calculated using the changes in unmet demand (profit gain or loss), changes in average inventory held (savings or additional cost) and the cost of implementing the plan (amount from BCP Choice Model used). This is put into practice by subtracting simulation results of simulation configurations reflecting the $\mathrm{BCP}$ in question from the results from the case of no response reconfiguration (expressed as 'BCP 128').

Net Savings $=$
$[($ Unmet Demand BCP 128) - (Unmet Demand BCP Y $)] * \$ 2.40$ profit/unit
$+\left[\left(\right.\right.$ BCP 128 Ave.OEM Inventory) - (BCP Y Ave.OEM Inventory) ${ }^{*} \$ 2.00(.4)$ holding/unit
- BCP Y Cost of Implementation

\section{Figure 3.5: Post Discrete-Event Simulation Cost Analysis}

Examples of a table with units measured converted to dollar savings under each $\mathrm{BCP}$ are shown (Tables 3.11 and 3.12). 


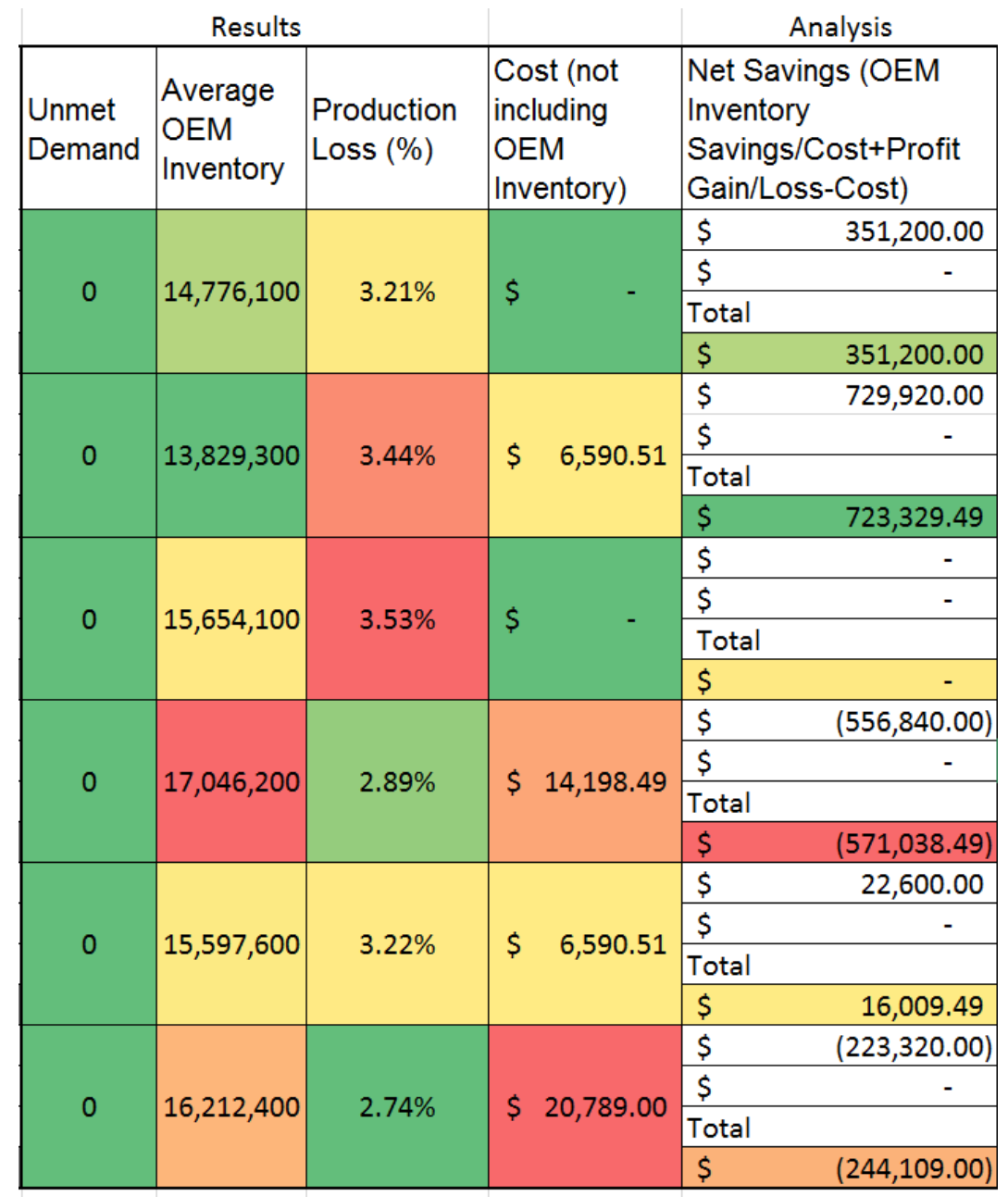

Table 3.11: Example Cost Analysis of Discrete-Event Simulation Results

$\mathrm{BCP}$ results are then compared by the Net amount of dollars saved and color-coded in rank to show which is the most monetarily preferable $\mathrm{BCP}$, in terms of profit loss and implementation cost. The example plot graph (Figure 3.6) provides further visual support to those who are analyzing the best responses to the risk in their supply chain network by indicating (by the red line) the point at which cost and savings are equal, and whether the savings of a plan falls above the cost and by how much. 


\begin{tabular}{|c|c|c|c|c|c|c|c|}
\hline & & Change in Loss & $>$ & & Response & Amount Saved & \\
\hline 1 & $\$$ & $5,872,230.00$ & $\mathrm{Y}$ & $\$$ & $851,177.80$ & $\$$ & $5,021,052.20$ \\
\hline 2 & $\$$ & $5,248,230.00$ & $Y$ & $\$$ & $215,673.00$ & $\$$ & $5,032,557.00$ \\
\hline 3 & $\$$ & $5,638,230.00$ & $Y$ & $\$$ & $426,798.23$ & $\$$ & $5,211,431.77$ \\
\hline 4 & $\$$ & $5,833,230.00$ & $Y$ & $\$$ & $850,885.80$ & $\$$ & $4,982,344.20$ \\
\hline 5 & $\$$ & $4,858,230.00$ & $Y$ & $\$$ & $3,073.33$ & $\$$ & $4,855,156.67$ \\
\hline 6 & $\$$ & $4,468,230.00$ & $Y$ & $\$$ & $210,125.00$ & $\$$ & $4,258,105.00$ \\
\hline 7 & $\$$ & $4,078,230.00$ & $Y$ & $\$$ & $853,805.80$ & $\$$ & $3,224,424.20$ \\
\hline 8 & $\$$ & $3,688,230.00$ & $Y$ & $\$$ & - & $\$$ & $3,688,230.00$ \\
\hline
\end{tabular}

Table 3.12: Choice Model, Example Choice Cost vs. Benefit Comparison

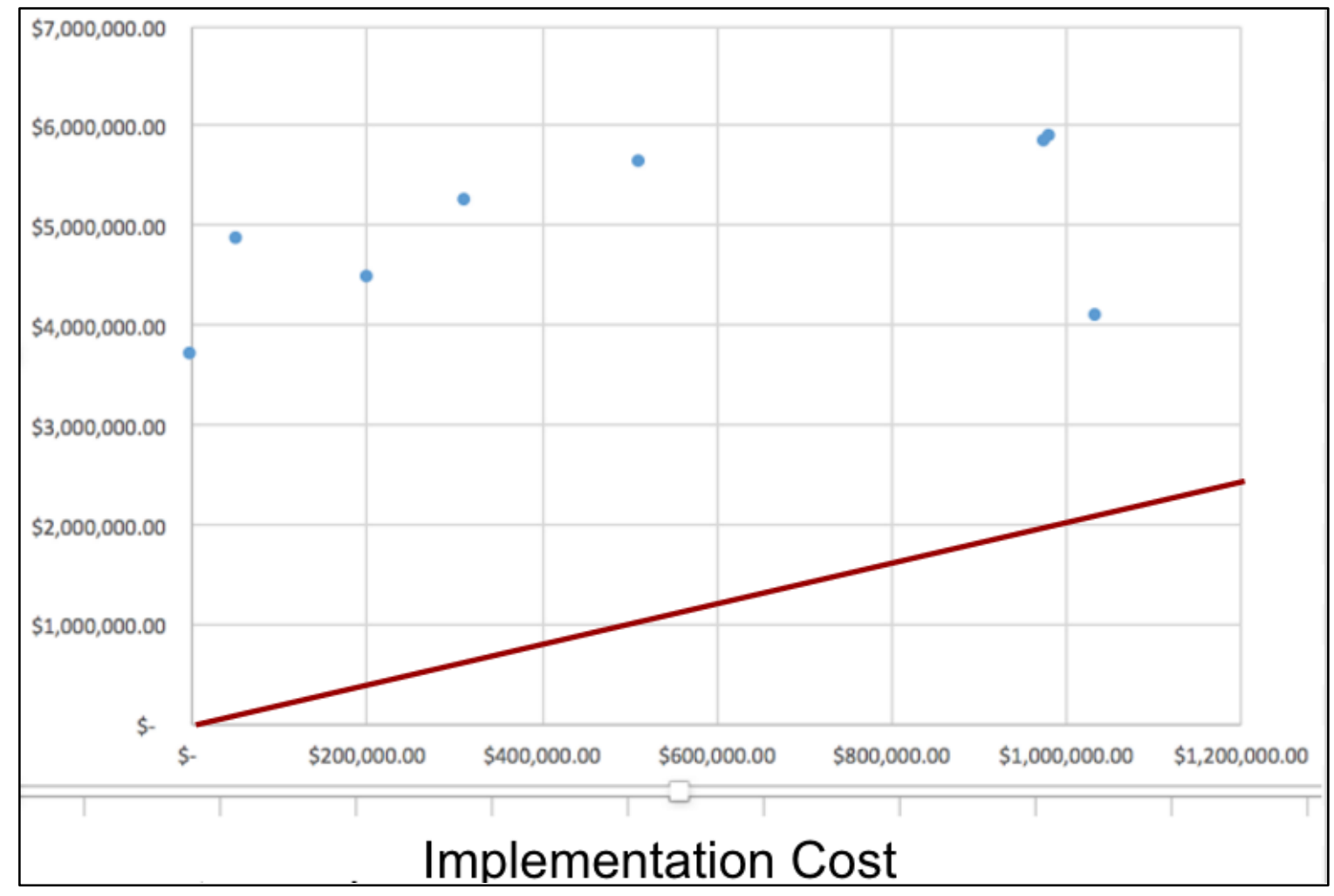

Figure 3.6: Choice Model, Example Scatter Plot Representation of Choices

The setup of this model is feasible across many supply chain situations. Various response choices are listed and tested, according to the change in disruption frequency and impact that they cause. A rough cut of optimal response combinations is done using the BCP Choice Model, a 
knapsack optimization problem which narrows down the choices of response that will cause the most savings. A discrete-event simulation model uses the same risk probability distributions, according to the characteristics of the supply network being analyzed. This simulation is used to test both the outcomes of the supply network's vulnerability to disruption and the monetary outcome of implementing a set of response strategies. The discrete-event simulation model ultimately serves to provide the most accurate prediction of the reduction in losses due to disruption after a response has been implemented. 


\section{Chapter 4 - SYSTEM IMPLEMENTATION}

This chapter describes the variety of details required for configuring, running, and reconfiguring the simulation and cost-analysis decision support models and explains a real supply chain scenario that was used to do so. In order to run the simulation, a survey was required for obtaining data. Data collection for this experiment consisted of an emailed survey to a representative from Company XYZ, a large manufacturing company. Responses to questions regarding supply chain configuration, risk, and response plans were requested in order to model the case and are shown below (Supply Chain Professional, personal communication, 2015).

\section{Supply Chain Disruption Risk Management Survey and Case 1 Input}

1. Is this a required component for all products or a product with its own independent demand from customers?

$<<$ It's a required component for all products.

2. Please share, if possible, the rate of production and the inventory holding policies for this item. $<$ The inventory is 40 days of production

3. Corresponding suppliers and/or locations for afore mentioned components $<<$ Three suppliers, all located in Japan.

4. Average demand (daily, weekly, or monthly) for the final product? $<<50$ million units/quarter

5. Profit margin per item?

$<<$ Cost is $\$ 4$ per unit, margin is $60 \%$. (That is, profit $\$ 4=.6$ or profit is $\$ 2.40$ per unit.)

6. Disruption/disaster occurrence(s)- date and number of days supplier(s) down $<<$ Tsunami in 2011; one week.

7. Recorded loss (unit or $\$$ sales, market share, physical loss) due to afore-mentioned disruption $<<5 \%$ Production loss.

8. Mitigation plans in place prior to disruption including second sourcing, inventory and sourcing choices?

$<<$ Qualify contingent suppliers. 
9. Was inventory holding for the purpose of disruption planning considered as well? What kind of risk assessment was already in place? Where are the contingent suppliers located?

$<$ Yes. The contingent suppliers are in Taiwan and Korea.

10. What are the extra costs are associated with sourcing to contingent suppliers in the event of disruption?

$<20$ headcount work for 1 year, total estimate $\sim \$ 3 \mathrm{M}$.

11. Actions taken after the disruption occurrence(s)?

$<<$ Understand the severity of the impact.

12. What actions were taken immediately after the event in order to recover? Were contingent suppliers used? Did the company help rebuild disrupted facilities?

$\ll$ No immediate action in place. Contingent suppliers take 1 year to qualify. No help from the company to rebuild the facilities.

To summarize, the results of the survey were as follows:

- Supply Network: Three suppliers (2nd tier) in Fukushima and Sendai area of Japan.

Company factory in Japan.

- Rate of Production: to match demand

- Inventory level: 40 days of production

- Average demand: 50 million units/quarter; Demand arrival at 50 million units per quarter, or 548,000/day (going off of 365 day business year).

- Number of days suppliers were down: 7

- Production loss: $<5 \%$ of production

- Contingency plan: Second sourcing to suppliers in Taiwan and Korea

- Extra cost of continuity plan: $\$ 3$ million

- All quantities reduced to 1/1000 for purpose of not overworking model. 
- Failure rates and time down distribution (reliability logic) set according to estimates of disruptive risk in region.

- Each source (since all delivering same material) set to have initial arrival rate of 760 units per hr (random.exponential(1hr)).

- Experimentation should show unmet demand, sales, average inventory of finished goods and percent production loss.

The following actions were required for the model configuration:

- Set up suppliers, sources, OEM factory, combiner, sales sink, demand source, unmet demand sink.

- Create status labels for count of entries into sales, unmet demand sinks and combiner buffer contents.

- Create an entity for unit(s) and an entity for Demand.

- Set reliability logic to 'Calendar Based' for each server that may be disrupted.

- Program reliability distributions into each of these servers.

- Create three different source entities directed to the three respective supplier locations.

- Set the component arrival rate for all sources to 27 arrivals per day.

- Set inventory to 250 units at the combiner (input buffer capacity).

- Program that any other unit of product must waits at the assembly output buffer (infinite capacity).

- Offset demand generation by fifteen days to allow for buildup of inventory, then set the rate of arrival to 25 entries per day. 


\section{Data Configuration}

A variety of actions were required in order to translate the data received from the company into a usable format for the discrete-event simulation and choice models.

The supply chain configuration for Case 1 was simulated according to the flow of supply and demand taken from the previously mentioned survey and disruption risk vulnerability. The model simulates losses under these configurations and compares them to the actual historical data, providing a proof of the accuracy of the vulnerability model in Simio.

\section{Risk Data Collection}

It was necessary that the author research information regarding disruption risks in the regions specified by Company XYZ. The most complete and reliable source of publically available information regarding disasters across the globe proved to be the, "Global Risk Data Platform," a map found on PreventionWeb.com. The "Basic Country Statistics and Indicators" (2014) found on PreventionWeb.com indicated the top risks present in Japan, and these top risks (flooding, volcanic eruptions, landslides, storm surge/tsunami) were then searched for on the Global Risk Data Platform map (Basic Country Statistics and Indicators, 2014).

In order to translate the available data on Preventionweb.com maps into programmable form, the following actions were taken. According to the maps included (Appendix A), information regarding natural disaster risk was collected. Part of coming up with risk probability and severity information was understanding the many different ways that this information is expressed publically (dollar loss, mortality, etc. on the dynamic map). 
For the Fukushima node risk profile, probabilistic distributions were generated using the information shown in the table below, where the common disaster, information source, deduced interarrival/probability of disruption, and average days down predicted are listed (Tables 4.1-4.3).

\begin{tabular}{|c|c|c|c|}
\hline Disruption Type & $\begin{array}{l}\text { Source of Information/ Data } \\
\text { Found }\end{array}$ & $\begin{array}{l}\text { Ave. Interarrival } \\
\text { Time }\end{array}$ & $\begin{array}{l}\text { Ave. Days } \\
\text { Down }\end{array}$ \\
\hline $\begin{array}{l}\text { Earthquake and } \\
\text { Tsunami }\end{array}$ & $\begin{array}{l}\text { Earthquake intensity zones } \\
\text { indicate where there is a } 20 \% \\
\text { probability that degrees of } \\
\text { intensity shown on the map will } \\
\text { be exceeded in } 50 \text { years. Or } \\
100 \% \text { chance a considerable } \\
\text { intensity will be reached in } 50 \\
\text { years } \\
60 \text { people/year affected; } 1000 \\
\text { people affected in order to } \\
\text { merit an event at plant }\end{array}$ & $\begin{array}{l}18,248 \text { days } \\
\text { between events, or } \\
0.00547945 \% \\
\text { chance of } \\
\text { occurrence. }\end{array}$ & $\begin{array}{l}3 \text { weeks } \\
\text { (historical) }\end{array}$ \\
\hline $\begin{array}{l}\text { Flooding (river } \\
\text { and flash) }\end{array}$ & Dynamic PreventionWeb Map & $\begin{array}{l}1000 / 60=16 \\
\text { years or } \\
5840 \text { days } \\
\text { between events; } \\
.01712329 \% \\
\text { chance of } \\
\text { occurrence }\end{array}$ & $\begin{array}{l}1 \text { week }(1000 \\
\text { people } \\
\text { affected) } \\
\text { Estimated } \\
\text { (lower) in } \\
\text { comparison to } \\
\text { Earthquake } \\
\text { average }\end{array}$ \\
\hline Landslides & $\begin{array}{l}\text { Appendix A, Map 3; } 1000 \\
\text { people affected per year }\end{array}$ & $\begin{array}{l}365 \text { days between } \\
\text { events, or } .274 \% \\
\text { chance of } \\
\text { occurrence }\end{array}$ & 5 days \\
\hline $\begin{array}{l}\text { Volcanic } \\
\text { Eruption }\end{array}$ & $\begin{array}{l}\text { Appendix A, Map 2; } \\
\text { Nearby active volcanoes: } 2 \text {, } \\
\text { Mount Adatara ( } 3 / 100 \text { yrs) and } \\
\text { Mount ( } 5 / 100 \text { yrs) } \\
\text { From past events; } \\
\text { http://volcano.si.edu/region.cfm } \\
\text { ?rn=8 }\end{array}$ & $\begin{array}{l}4562.5 \text { days } \\
\text { between } \\
\text { occurrences, or } \\
.02191 \% \text { chance } \\
\text { of occurrence. }\end{array}$ & 5 days \\
\hline
\end{tabular}

Table 4.1: Fukushima Risk Profile 
Likewise, the risk information gathered and deduced for two locations in Sendai, Japan (the first more inland than the second) are shown (Tables 4.2 and 4.3).

\begin{tabular}{|c|c|c|c|}
\hline Disruption Type & $\begin{array}{l}\text { Source of Information/ Data } \\
\text { Found }\end{array}$ & $\begin{array}{l}\text { Ave. Interarrival } \\
\text { Time }\end{array}$ & $\begin{array}{l}\text { Ave. Days } \\
\text { Down }\end{array}$ \\
\hline $\begin{array}{l}\text { Earthquake and } \\
\text { Tsunami }\end{array}$ & $\begin{array}{l}\text { Earthquake intensity zones } \\
\text { indicate where there is a } 20 \% \\
\text { probability that degrees of } \\
\text { intensity shown on the map } \\
\text { will be exceeded in } 50 \text { years. } \\
\text { Or } 100 \% \text { chance a } \\
\text { considerable intensity will be } \\
\text { reached in } 50 \text { years }\end{array}$ & $\begin{array}{l}18,248 \text { days } \\
\text { between events, or } \\
0.00547945 \% \\
\text { chance of } \\
\text { occurrence; est. } \\
\text { same as in } \\
\text { Fukushima. }\end{array}$ & 3 weeks \\
\hline $\begin{array}{l}\text { Storm Surge } \\
\text { (due to Typhoon } \\
\text { or cyclone) }\end{array}$ & $\begin{array}{l}\text { Appendix A } \\
100 \text { people affected per year } \\
\text { by cyclone }\end{array}$ & $\begin{array}{l}3650 \text { days between } \\
\text { events, or } .0274 \% \\
\text { chance of } \\
\text { occurrence }\end{array}$ & 3 weeks \\
\hline Landslide & 1000 people affected per year & $\begin{array}{l}365 \text { days between } \\
\text { events, or } .274 \% \\
\text { chance of } \\
\text { occurrence; est. } \\
\text { same as in } \\
\text { Fukushima. }\end{array}$ & 5 days \\
\hline
\end{tabular}

Table 4.2: Sendai Risk Profile 


\begin{tabular}{|l|l|l|l|}
\hline Disruption Type & $\begin{array}{l}\text { Source of Information/ Data } \\
\text { Found }\end{array}$ & $\begin{array}{l}\text { Ave. Interarrival } \\
\text { Time }\end{array}$ & $\begin{array}{l}\text { Ave. Days } \\
\text { Down }\end{array}$ \\
\hline \multirow{4}{*}{$\begin{array}{l}\text { Earthquake and } \\
\text { Tsunami }\end{array}$} & $\begin{array}{l}\text { Earthquake intensity zones } \\
\text { indicate where there is a 20\% } \\
\text { probability that degrees of } \\
\text { intensity shown on the map } \\
\text { will be exceeded in 50 years. } \\
\text { Or 100\% chance a } \\
\text { considerable intensity will be } \\
\text { reached in 50 years }\end{array}$ & $\begin{array}{l}\text { in the year or } \\
18,250 \text { days } \\
\text { between } \\
\text { occurrences; est. } \\
\text { same as in } \\
\text { Fukushima. }\end{array}$ & 3 weeks \\
\hline $\begin{array}{l}\text { Storm Surge (due } \\
\text { to Typhoon or } \\
\text { cyclone) }\end{array}$ & $\begin{array}{l}\text { 1 surge per 10 years plus } \\
\text { cyclone 100-1000 ppl/yr }\end{array}$ & $\begin{array}{l}\text { 0.19178\% chance } \\
\text { in the year or } \\
521.4 \text { days } \\
\text { between } \\
\text { occurrences }\end{array}$ & 3 weeks \\
\hline \multirow{2}{*}{$\begin{array}{l}\text { Flooding } \\
\text { "Floods.Pop.Exp:: "Dynamic" }\end{array}$} & $\begin{array}{l}\text { 0\% chance; } \\
\text { interarrival time } \\
\text { not applicable }\end{array}$ & NA \\
\hline
\end{tabular}

Table 4.3: Sendai Location 2 Risk Profile

After the risk data was collected and translated into average days, the Monte Carlo

simulation was run to generate exponential and triangular distributions for all events considered at each site. The base (pre-response) risk profile distributions per site, summarized in Table 4.4, were then programmed into the reliability logic of the Simio model.

\begin{tabular}{|l|l|l|l|}
\hline Location & Fukushima & Sendai1 (City Proper) & Sendai2 (Tagajo) \\
\hline Frequency (Days Between) & $\operatorname{Exp}(211.29)$ & $\operatorname{Exp}(244.05)$ & $\operatorname{Exp}(455.2)$ \\
\hline Days Down & $\operatorname{Tri}(2.05,6.49,10.92)$ & $\operatorname{Tri}(2.36,7.81,13.27)$ & $\operatorname{Triangular}(1.64,21.26,40.88)$ \\
\hline
\end{tabular}

Table 4.4: Case 1 Pre-Response Node Risk Parameters

\section{Part 2 Implementation of Response Testing}

Two types of responses at each of the three supplier locations and one possible response at 
the OEM site were considered for Case 1 , resulting in $2^{\wedge} 7$, or 128 , combinations of yes/no responses to check.

The individual responses tested an increase of inventory at the supplier site by three days worth of production and to send production to a second source, at each of the three supplier sites, resulting in six 'yes or no' choices. Additionally, a seventh choice was tested, to decrease the amount of inventory held at the OEM by three days of production. It should be noted that the model is capable of analyzing more than three types of responses through the use of optimization programming to analyze, for instance, 4,096 different response enumerations.

\section{Response Impact Configuration}

Response impact was modeled by inputting percent changes in the days between disruption occurrences and percent changes in the days down at each site (Table 4.3). Some of this information was estimated in the implementation of this particular case. Namely, estimates were made regarding the change to risk data under a response choice as well as the amount that such responses would cost. Specific information provided by Company XYZ that was used includes that the responses in place in 2011 were second sourcing and an OME inventory policy. Subsequently, the cost of both of these response choices as specified by Company XYZ were implemented 


\begin{tabular}{|c|c|c|c|c|c|c|c|c|c|c|c|c|}
\hline \multirow[b]{2}{*}{ Supplier } & \multirow[b]{2}{*}{ Risk } & \multirow[b]{2}{*}{ Probability Before } & \multicolumn{3}{|c|}{ Days Down Before } & \multirow[b]{2}{*}{ Response } & & & \multicolumn{4}{|c|}{ Post-Response Days Down } \\
\hline & & & Mediar & & Max & & \multicolumn{2}{|c|}{ Probability Post-Response } & Change & Mediar & Min & Max \\
\hline \multirow[t]{8}{*}{ Fukushima } & 1 & $5.47945 \mathrm{E}-05$ & 21 & 1 & 42 & c & Same & $5.47945 \mathrm{E}-05$ & -3 & 18 & 0 & 39 \\
\hline & 3 & 0.000171233 & 10 & 4 & 20 & & Same & 0.000171233 & -3 & 7 & 1 & 17 \\
\hline & 4 & 0.002739726 & 5 & 10 & 2 & & Same & 0.002739726 & -3 & 2 & 7 & 0 \\
\hline & 5 & 0.000219178 & 5 & 10 & 1 & & Same & 0.000219178 & -3 & 2 & 7 & 0 \\
\hline & 1 & & & & & d & $75 \%$ & $4.10959 \mathrm{E}-05$ & $50 \%$ & 10.5 & 0.5 & 21 \\
\hline & 3 & & & & & & $110 \%$ & 0.000188356 & $110 \%$ & 11 & 4.4 & 22 \\
\hline & 4 & & & & & & $0 \%$ & 0 & $0 \%$ & 0 & 0 & 0 \\
\hline & 5 & & & & & & $0 \%$ & 0 & $0 \%$ & 0 & 0 & 0 \\
\hline \multirow[t]{6}{*}{ Sendai1 } & 1 & \#DIV/0! & \#REF! & & & c & Same & $5.47945 \mathrm{E}-05$ & 0 & \#REF! & & \\
\hline & 2 & \#DIV/0! & \#REF! & & & & Same & 0.000171233 & 0 & \#REF! & & \\
\hline & 3 & \#DIV/0! & \#REF! & & & & Same & 0.002739726 & 0 & \#REF! & & \\
\hline & 1 & & & & & d & $75 \%$ & $4.10959 \mathrm{E}-05$ & $50 \%$ & 10.5 & & \\
\hline & 2 & & & & & & $110 \%$ & \#DIV/0! & $110 \%$ & 11 & & \\
\hline & 3 & & & & & & $0 \%$ & \#DIV/O! & $0 \%$ & 0 & & \\
\hline \multirow[t]{4}{*}{ Sendai2 } & 1 & \#DIV/0! & \#REF! & & & c & Same & $5.47945 \mathrm{E}-05$ & 0 & \#REF! & & \\
\hline & 2 & \#DIV/0! & \#REF! & & & & Same & 0.000171233 & 0 & \#REF! & & \\
\hline & 1 & & & & & d & $75 \%$ & 4.10959E-05 & $50 \%$ & 10.5 & & \\
\hline & 2 & & & & & & $110 \%$ & \#DIV/0! & $110 \%$ & 11 & & \\
\hline
\end{tabular}

Table 4.5: Case 1, Response Choice Model, Sensitivity Input

For 'Response Sensitivity' configuration, user input, highlighted in yellow in Table 4.5, generated new 'post-response' values. Logical assumptions for results of Company XYZ's responses were made. For instance, for the response strategy of holding extra inventory, the probability of disruption risk stayed the same because holding inventory does not affect the disruptive event itself. However, days down under the response of holding inventory showed a -3 day change due to the choice of inventory quantity being set at 3 days-worth of production, which directly reduces the days the supplier is down. 'Second Sourcing to Supplier B' involved an assessment of risk frequency and days down at a completely new supplier site, which, as indicated by Company XYZ, is located in Taiwan. Risk research for Taipei showed no risk of Volcanic Eruption. Thus, the Volcanic Eruption risk change cell was set at $0 \%$, along with other percentage changes for frequency and days down for the other listed risks. It should be noted that this model only considers the risks that exist at the original supplier location. Risks that exist in Taipei but 
not in Fukushima are not added to the model. Adding this functionality to the model illustrates an area for future work and for a more thorough BCP analysis when involving second sourcing.

\begin{tabular}{|c|c|c|c|}
\hline (2) Assist with resilience & (3) Hold X more Inventory & (4) Second Source & (5) Assist with Supplier Recovery \\
\hline =(cost.hourslabor@A)+(cost.infrastruc@A) & =cost.holding@A*365 & Given*Probability of Occurrence & $=($ cost.infrastructure@A)*P(dis) \\
\hline =(cost.hourslabor@B)+(cost.infrastruc@B) & =cost.holding@B*365 & Given*Probability of Occurrence & $=\left(\right.$ cost.infrastructure@B ${ }^{*} \mathrm{P}($ dis $)$ \\
\hline =(cost.hourslabor@C)+(cost.infrastruc@C) & =cost.holding@C*365 & Given*Probability of Occurrence & $=($ cost.infrastructure@C)*P(dis) \\
\hline
\end{tabular}

Table 4.6: Case 1, Response Choice Model Cost Input

Parameters were entered for calculating the cost of each response at each node (Table 4.6). For instance, Company XYZ said that extra costs associated with second-sourcing were a 20person headcount for one year of work estimated at $\$ 3$ million. The inventory cost of $40 \%$ of the value of the inventory was used for the calculation of cost per unit of inventory specified at each site. The model could easily take into account any potential disruption risks at the OEM site itself by adding lines to the spreadsheet (Table 4.6) for each of the risks and adding it to the overall Risk Index Comparison. A limitation of the model that can be amended is the ability to program in a variety of inventory policy choices, both at the OEM and supplier levels. This model only considers one policy at a time; however, multiple policies could be compared by providing input into the costing and risk comparison model just as the yes or no choices already present in the model are considered. Accordingly, the number of enumerations required to optimize the set of BCP decisions increases exponentially with each additional choice, and an area of future work could be to select ideal inventory levels prior to testing in the BCP Choice Model.

\section{Simio Testing of Best Response Plans}

The following response configurations (Table 4.7) found from the optimization model were tested in the Simio simulation model. According to the methodology, these BCPs' (Y/N combinations) corresponding parameters (Table 4.7) were then plugged into the Simio model for 
further testing. The first two responses included the holding of extra inventory at the OEM site, whereas the following six are the response plans that do not include a change in OEM inventory policy and exhibited the highest net savings.

The resulting multi hazard risks were checked for accuracy by ensuring that they were, for instance, consistent when a response was or wasn't modeled. These sets of reliability/risk parameters were then used in separate scenario runs in Simio to achieve results.

\begin{tabular}{|c|c|c|c|c|c|}
\hline BCP & Supplier & Probability & $\begin{array}{l}\text { DD } \\
\text { (Median) }\end{array}$ & OEM & $\begin{array}{l}\text { Average } \\
\text { interarriv } \\
\text { al time } \\
\text { (days) }\end{array}$ \\
\hline \multirow[t]{3}{*}{127} & 1 & 0.00477161 & 8.68950239 & Y & 209.5728 \\
\hline & 2 & 0.00400944 & 9.01014583 & & 249.4113 \\
\hline & 3 & 0.00222288 & 21.2067222 & & 449.8673 \\
\hline \multirow[t]{3}{*}{125} & 1 & 0.00474022 & 8.60053207 & $Y$ & 210.9607 \\
\hline & 2 & 0.00406917 & 8.79920821 & & 245.7507 \\
\hline & 3 & 0.00224995 & 20.2781039 & & 444.4538 \\
\hline \multirow[t]{3}{*}{128} & 1 & & & $\mathrm{~N}$ & \\
\hline & 2 & & & & \\
\hline & 3 & & & & \\
\hline \multirow[t]{3}{*}{95} & 1 & 0.0003148 & 11.3430854 & $\mathrm{~N}$ & 3176.662 \\
\hline & 2 & 0.0040134 & 9.03012313 & & 249.165 \\
\hline & 3 & 0.0022332 & 21.3859106 & & 447.7873 \\
\hline \multirow[t]{3}{*}{126} & 1 & 0.00468085 & 8.68444487 & $\mathrm{~N}$ & 213.6364 \\
\hline & 2 & 0.00403172 & 8.75549416 & & 248.0329 \\
\hline & 3 & 0.00219129 & 20.4442068 & & 456.3516 \\
\hline \multirow[t]{3}{*}{93} & 1 & 0.00031564 & 11.35352 & $\mathrm{~N}$ & 3168.159 \\
\hline & 2 & 0.00401308 & 8.85987219 & & 249.1851 \\
\hline & 3 & 0.00223019 & 20.441109 & & 448.3921 \\
\hline
\end{tabular}

Table 4.7: Case 1 Post-BCP Risk Parameters 


\section{Cases $1 A, 1 B$ and 2 Implementation}

In addition to the implementation of the simulation model for Case 1, described above,

three other theoretical cases, 1A, 1B, and 2, were implemented for testing and will be described briefly in more detail in chapter 5.

Case 1: Company XYZ, historical data

Case 1A: An adjustment to Case 1 with different response scenario data

Case 1B: An adjustment to Case 1 inventory set-up for proof of concept

Case 2: A test of a variety of inventory policies

Case 1A was created through a reconfiguration of Case 1. All discrete-event simulation model setups remained the same and only a few changes were made to the BCP Choice Model. Namely, cost parameters in the BCP Choice model were altered to by eliminating the dollar savings at the OEM completely and reducing the cost of having any supplier hold additional inventory to ten percent of what the original Case 1 model specified ( $\$ 66,000$ as opposed to $\$ 660,000$ per site per year).

For Case 1B, the discrete-event simulation implementation remained the same as in Case 1; however, the BCP Choice Model involved a change to implementation. OEM inventory level was set to fourteen days of production, as opposed to 40 days production, and the 'OEM inventory change' response choice was eliminated, resulting in 64 response combinations, as opposed to 128 to be tested. Finally, the cost parameter for more inventory held at a supplier was decreased to five percent of the cost implementation in the original Case 1 choice model, to assume that the cost of having a supplier hold more inventory would be a small fraction of the actual cost to the supplier of holding more inventory. 
Lastly, Case 2 required all the same parameters from Case 1, including production and demand rates, supplier inventory level and supply network configuration and the baseline (preresponse) risk parameters at servers. However, risk parameters were not altered for Case 2 scenarios in order to isolate the testing of changed inventory policy at the OEM.

To summarize, after the successful implementation of a historical case study, multiple variations on that case were implemented. Details regarding the results of the scenarios summarized will be discussed in the following chapter. 


\section{Chapter 5 - TESTING AND EVALUATION}

The following four cases, one involving real data from a company that experienced a supply chain disruption, a case which is a variation on Case 1, and two cases testing theoretical changes to this data, serve as proofs of the concept and analysis. Conclusions from input and output data will be made here, as will insights into the configuration and effectiveness of the models. The cases mentioned in Chapter 4 were developed in the process of analyzing initial test results and this process will be described further here. An outline of the cases is as follows:

Case 1: Company XYZ, historical data

Case 1A: An adjustment to Case 1 with different response scenario data

Case 1B: An adjustment to Case 1 inventory set-up for proof of concept

Case 2: A test of a variety of inventory policies

\section{Case 1 Testing}

Case 1 was as an initial system implementation using real historical data from a large manufacturing company, which will be called Company XYZ. For Part 1, a simulation model mirroring the setup of the real supply chain was created and checked for accuracy and showed affirmative results. Namely, Company XYZ reported a production loss of less than 5\%, and this was the recorded output.

Prior to verifying the accuracy of loss in the simulation model, various adjustments were made to the configuration of the model, based on the results of running the simulation. Namely, production and demand rates were adjusted. 


\begin{tabular}{|l|l|l|l|l|l|l|}
\hline No Risk, Shelf only & Compl... & 10 & 10 of 10 & 3605 & 23 & 197555 \\
\hline No Risk, Inventory Buffer & Compl... & 10 & 10 of 10 & 0 & 22069.9 & 202460 \\
\hline & & & & & & \\
\hline & Compl... & 10 & 10 of 10 & 0 & 21958.8 & 201289 \\
\hline Historic Case (Risk and 22080 Inventory) & & & & & & \\
\hline
\end{tabular}

Table 5.1: Case 1, Scenarios 1-4 results, Simio interface

The above scenarios (Table 5.1) were initially run under a simulation configuration of 10,000 product arrivals per hour per source, or 30,000 product arrivals per hour. At the same time, demand was set as specified by Company XYZ to approximately 23,000 per hour. This initial imbalance in supply and demand was chosen in order to ensure that the desired inventory policy was achieved. Results in Tables 5.1-5.5 show average unmet demand, average inventory, and total sales for their corresponding scenarios.

While the 23,000 to 30,000 demand/supply ratio did keep inventory levels at desired policy levels, reconfiguration of the supply to demand ratio was chosen due to the fact that the risk scenario in which no inventory was held and disruption risk existed resulted in zero unmet demand. This does not reflect what would theoretically be true.

Instead of supplying 30 units per hour and demanding 23 units per hour (ratio of 30:23), supply and demand were both set at 24 units per hour (24:24). (Each server supplying 6 units per hour). The results were as follows (Table 5.2).

Table 5.2: Case 1, Scenario 6 results, Simio interface 
With this supply/demand configuration, the, "no risk, inventory," scenarios were run again with the following results (Table 5.3).

No Risk, 23040 Iventory, Matched S/D Compl... \begin{tabular}{|l|l|l|}
10 & 10 of 10 & 36057.9
\end{tabular} 10 175058

Table 5.3: Case 1, Scenario 7 results, Simio interface

This adjustment provided a more accurate result- supply was greater than demand.

Further, it more accurately reflects the likelihood of supply and demand being matched even if it means that the desired inventory policy not being achieved in the model.

The average inventory held was 3443.1 units for these scenarios, when the policy called for it to have been 23,040 units. Using the Simio model interface, investigation was done into whether the inventory was filled before delayed demand started. Indeed, it was; however, throughout the duration of the simulation, the desired amount of inventory was not maintained.

Due to the amount of unmet demand under no risk and the fact that average inventory was almost $1 / 10$ th of the policy desired, supply was increased again, but this time to a smaller supply/demand ratio.

The newly gaged model had a ratio of 25:23 (Inventory policy back to 22,080). Results were as follows (Table 5.4).

No Risk, 22080 + S Inv., 25:23 S:D

Table 5.4: Case 1, Scenario 9 results, Simio interface

Since no unmet demand was an accurate result of no risk, the configuration was run under risk parameters, with the following results (Table 5.5).

Table 5.5: Case 1, Scenario 10 results, Simio interface 
Further investigation into the simulation results depicted in the Simio pivot table demonstrated that the supplier servers failed on average 2.2, 1.2 and 1.1 times per year for average total times down of 327,614 , and 203 hours, respectively, or $13.6,25.6$, and 8.5 simulated days. Thus, the failure rate was not unlike that of company XYZ's year 2011. After testing under various configurations and extremes, this set-up should provide the most accurate results for the impact of the risk programmed into the system.

\section{System Verification}

An unmet demand of zero was modeled in this simulation, but production loss results showed did occur. Production loss was measured in the simulation model by the quantities of raw material not sold to the disrupted supplier(s) or the percentage of units that were discarded into the respective source sinks during server failures due to halted flow and filled capacity at the server buffers.

In the Case 1 model configuration runs, the Simio pivot chart reported a total of 16,239 units of production loss (to sinks) out of 222,109 units produced, or an average of $7.31 \%$ production loss. While this percentage does not meet the criteria of the real data (under 5\%), production loss was in the 'no risk' simulation scenario must be considered. The question arose of whether there was a certain amount of 'lost product' from the sources due simply to the inventory limits of the servers. In fact, in the model in which no failures were programed but all other parameters were set, production loss was 13,759 out of 222,556 units, or $6.18 \%$. Thus, it can be inferred that the disruptions in the 'Risk' model resulted in a $1.13 \%$ increase in production loss and that Company XYZ's, "Less than 5\% production loss," was indeed accurately simulated, 
accurately portraying the year 2011 for company XYZ in terms of its losses ( $<5 \%$ production) and occurring with models in which the historic inventory policy (40 day's demand) are kept.
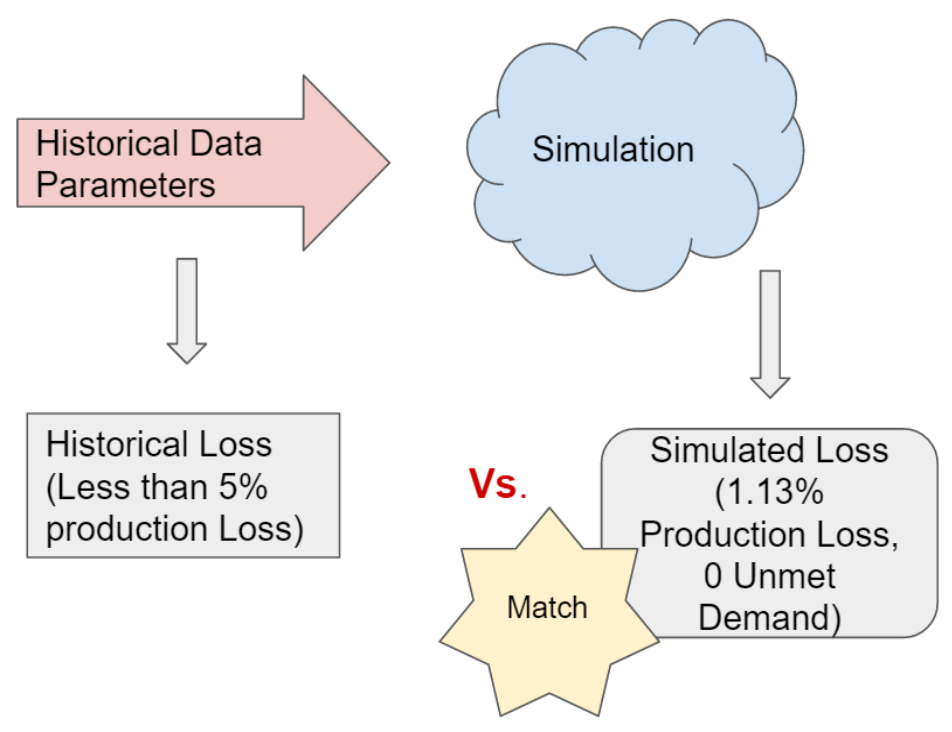

Figure 5.1: Testing for Model Accuracy

The fact that production loss was $6.18 \%$ with no risk indicates that the arrival rate of supply for production was faster than production itself, thus resulting in product loss at source sinks. A test was done to confirm this by running the 'No risk' simulation with a lower supply rate, 24:23. The method with which to measure production loss, comparing the amount of units not used from the original sources to the final amount of units sent to the combiner to meet demand, shows higher values for reasons not related to supplier disruption.

\section{Part 2 Testing}

Since no historical data regarding the effectiveness of response strategies was available for Company XYZ, Part 2 of Case 1 employed theoretical response choices, logic, and parameters to prove the effectiveness of this decision support model. From the theoretical response parameters, 
the results below were found from the choice model and listed in order according to the highest net savings (Table 5.6).

In the scenarios shown in Table 5.6, the greatest net savings are the BCPs in which a decrease in inventory was made at the OEM site. This result was due to the fact that the cost calculation in these cases came out as negative, as savings instead of extra costs because of a reduction in the inventory holding expenses. Therefore the most optimal choice, according to net savings, was that in which turned out to be a decreased inventory. Even though the top response combination includes a negative quantity in the 'Savings' column, the extent of cost reduction due to holding inventory still outweighs any savings from other response plans.

Due to the fact that most of these top choices were response combinations that included the decision to decrease the amount of inventory held at the OEM, the response combinations (ranking 63-68) where the greatest net savings were indicated but had no change in inventory held at the OEM were also considered, as shown in Table 5.7. Consideration of choices that don't include the OEM inventory change is important in the case that the results of that choice are not as extreme in the simulation testing as in the choice model.

\begin{tabular}{|c|c|c|c|c|c|c|c|c|c|c|c|}
\hline BCP & SaI & & Cost & Net Savings & $\begin{array}{l}\text { Node1 } \\
\text { /Respo } \\
\text { nseC }\end{array}$ & $\begin{array}{l}\text { Node1 } \\
\text { /Respo } \\
\text { nseD }\end{array}$ & $\begin{array}{l}\text { Node2 } \\
\text { /Respo } \\
\text { nseC }\end{array}$ & $\begin{array}{l}\text { Node2 } \\
\text { /Respo } \\
\text { nseD }\end{array}$ & $\begin{array}{l}\text { Node3 } \\
\text { /Respo } \\
\text { nseC }\end{array}$ & $\begin{array}{l}\text { Node3 } \\
\text { /Respo } \\
\text { nseD }\end{array}$ & $\begin{array}{l}\text { OME } \\
\text { Invento } \\
\text { Change }\end{array}$ \\
\hline 127 & $\$$ & $(7,260.257)$ & $\$(691,200.00)$ & $\$ 683,939.74$ & $\mathrm{~N}$ & $\mathrm{~N}$ & $\mathrm{~N}$ & $\mathrm{~N}$ & $\mathrm{~N}$ & $\mathrm{~N}$ & $Y$ \\
\hline 125 & $\$$ & $(2,331.066)$ & $\$(684,609.49)$ & $\$ 682,278.42$ & $\mathrm{~N}$ & $\mathrm{~N}$ & $\mathrm{~N}$ & $\mathrm{~N}$ & $\mathrm{~N}$ & $Y$ & $\mathrm{~N}$ \\
\hline 96 & $\$$ & $2,413.492$ & $\$(677,001.51)$ & $\$ 679,415.00$ & $\mathrm{~N}$ & $Y$ & $\mathrm{~N}$ & $N$ & $\mathrm{~N}$ & $\mathrm{~N}$ & Y \\
\hline 88 & $\$$ & $14,309.251$ & $\$(664,708.94)$ & $\$ 679,018.19$ & $\mathrm{~N}$ & Y & $\mathrm{N}$ & $Y$ & $\mathrm{~N}$ & $\mathrm{~N}$ & Y \\
\hline 94 & $\$$ & $4,886.542$ & $\$(670,411.00)$ & $\$ 675,297.54$ & $\mathrm{~N}$ & $Y$ & $\mathrm{~N}$ & $\mathrm{~N}$ & $\mathrm{~N}$ & $\mathrm{Y}$ & $Y$ \\
\hline 86 & $\$$ & $16,158.221$ & $\$(658,118.43)$ & $\$ 674,276.65$ & $\mathrm{~N}$ & $Y$ & $\mathrm{~N}$ & $\mathrm{Y}$ & $\mathrm{N}$ & $\mathrm{Y}$ & $Y$ \\
\hline
\end{tabular}

Table 5.6: Case 1 Choice Model Results 


\begin{tabular}{|r|rrr|rr|l|l|l|l|l|l|l|l|}
\hline 128 & $\$$ & $(106.588)$ & $\$$ & - & $\$$ & $(106.59)$ & $\mathrm{N}$ & $\mathrm{N}$ & $\mathrm{N}$ & $\mathrm{N}$ & $\mathrm{N}$ & $\mathrm{N}$ & $\mathrm{N}$ \\
95 & $\$$ & $9,346.828$ & $\$$ & $14,198.49$ & $\$$ & $(4,851.67)$ & $\mathrm{N}$ & $\mathrm{Y}$ & $\mathrm{N}$ & $\mathrm{N}$ & $\mathrm{N}$ & $\mathrm{N}$ & $\mathrm{N}$ \\
\hline 3 & $\$$ & $21,634.136$ & $\$$ & $26,491.06$ & $\$$ & $(4,856.92)$ & $\mathrm{Y}$ & $\mathrm{Y}$ & $\mathrm{Y}$ & $\mathrm{Y}$ & $\mathrm{Y}$ & $\mathrm{N}$ & $\mathrm{Y}$ \\
126 & $\$$ & 957.564 & $\$$ & $6,590.51$ & $\$$ & $(5,632.95)$ & $\mathrm{N}$ & $\mathrm{N}$ & $\mathrm{N}$ & $\mathrm{N}$ & $\mathrm{N}$ & $\mathrm{Y}$ & $\mathrm{N}$ \\
93 & $\$$ & $12,606.582$ & $\$$ & $20,789.00$ & $\$$ & $(8,182.42)$ & $\mathrm{N}$ & $\mathrm{Y}$ & $\mathrm{N}$ & $\mathrm{N}$ & $\mathrm{N}$ & $\mathrm{Y}$ & $\mathrm{N}$ \\
\hline 87 & $\$$ & $17,065.525$ & $\$$ & $26,491.06$ & $\$$ & $(9,425.53)$ & $\mathrm{N}$ & $\mathrm{Y}$ & $\mathrm{N}$ & $\mathrm{Y}$ & $\mathrm{N}$ & $\mathrm{N}$ & $\mathrm{N}$ \\
\hline
\end{tabular}

Table 5.7: Case 1, Top Non-OEM Inventory Change Choices

This case demonstrates a reduction in the list of most cost-effective response choices prior to testing in the discrete-event simulation model.

\section{Cost-Benefit Ratio versus Net Savings}

Initially, results had been sorted according to the lowest cost-benefit ratio, or cost of implementation divided by resultant savings. However, net savings, the difference between the resultant amount saved and the cost of implementing the responses, demonstrated the greatest variability and provided the most tangible understanding of best choices.

\section{Case 1 Assessment in Simio}

According to the methodology, BCPs 127, 125, 128, 95, 126, and 93 and their corresponding risk parameters (Table 5.8) were tested in separate scenario runs in the Simio simulation model. 


\begin{tabular}{|r|r|r|r|r|r||}
\hline BCP & Supplier & Probability & $\begin{array}{l}\text { DD } \\
\text { (Median) }\end{array}$ & OEM & $\begin{array}{l}\text { Average } \\
\text { interarriv } \\
\text { al time } \\
\text { (days) }\end{array}$ \\
\hline 127 & 1 & 0.00477161 & 8.68950239 & Y & 209.5728 \\
\hline & 2 & 0.00400944 & 9.01014583 & & 249.4113 \\
\hline & 3 & 0.00222288 & 21.2067222 & & 449.8673 \\
\hline 125 & 1 & 0.00474022 & 8.60053207 & Y & 210.9607 \\
\hline & 2 & 0.00406917 & 8.79920821 & & 245.7507 \\
\hline & 3 & 0.00224995 & 20.2781039 & & 444.4538 \\
\hline 128 & 1 & & & $\mathrm{~N}$ & \\
\hline & 2 & & & & \\
\hline 95 & 3 & & & & \\
\hline & 2 & 0.0003148 & 11.3430854 & $\mathrm{~N}$ & 3176.662 \\
\hline & 3 & 0.0022332 & 21.3859106 & & 447.7873 \\
\hline 126 & 1 & 0.00468085 & 8.68444487 & $\mathrm{~N}$ & 213.6364 \\
\hline & 2 & 0.00403172 & 8.75549416 & & 248.0329 \\
\hline & 3 & 0.00219129 & 20.4442068 & & 456.3516 \\
\hline & 1 & 0.00031564 & 11.35352 & $\mathrm{~N}$ & 3168.159 \\
\hline & 2 & 0.00401308 & 8.85987219 & & 249.1851 \\
\hline & 3 & 0.00223019 & 20.441109 & & 448.3921 \\
\hline & & & & & \\
\hline
\end{tabular}

Table 5.8: Case 1 Post-BCP Risk Parameters

\section{Simulation Results and Cost Analysis}

The results measured by the simulation: unmet demand, average inventory held at the

OEM, sales and production loss, were used to assess the best BCP according to a cost analysis of these results. The Net Savings (Figure 5.2) according to the simulation model results (Table 5.9) were initially calculated by comparing the changes in cost of holding inventory (according to quantity held) and in sales (profit change). Change in unmet demand was not considered in this case because all results showed a value of zero for this measurement. The results of BCP 128 were used as a comparisons for the other BCP results because it involved no response choice implementations. 
Net Savings $2=$

[(Unmet Demand BCP 64) - (Unmet Demand BCP Y)] * \$2.40 profit/unit

$+[($ BCP 64 Ave.OEM Inventory) - (BCP Y Ave.OEM Inventory) $] * \$ 2.00(.4)$ holding/unit

$+[($ BCP 128 Sales $)-($ BCP Y Sales $)] * \$ 2.40$

Figure 5.2: Formula for Net Savings 2

\begin{tabular}{|c|c|c|c|c|c|c|c|c|c|c|}
\hline \multicolumn{6}{|c|}{ BCP Configuration } & \multicolumn{4}{|c|}{ Results } & \multirow{2}{*}{\begin{tabular}{|l} 
Analysis \\
Adjusted Net Savings \\
(Inventory/Profit/Total)
\end{tabular}} \\
\hline $\mathrm{BCP}$ & $\begin{array}{l}\mathrm{Y} / \mathrm{N} \\
\text { Combo }\end{array}$ & Node & Probability & $\begin{array}{l}\text { DD } \\
\text { (Median) }\end{array}$ & $\begin{array}{l}\text { Average } \\
\text { interarriv } \\
\text { al time } \\
\text { (days) }\end{array}$ & $\begin{array}{l}\text { Unmet } \\
\text { Demand }\end{array}$ & $\begin{array}{l}\text { Average } \\
\text { OEM } \\
\text { Inventory }\end{array}$ & Sales & $\begin{array}{l}\text { Production } \\
\text { Loss (\%) }\end{array}$ & \\
\hline \multirow[t]{4}{*}{127} & $\mathrm{~N}, \mathrm{~N}$ & & 0.00477161 & 8.68950239 & 209.5728 & \multirow{4}{*}{ 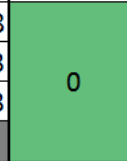 } & \multirow{4}{*}{$18,250,900$} & \multirow{4}{*}{$201,618,000$} & \multirow{4}{*}{$5 \%$} & $1,459,320.00$ \\
\hline & $\mathrm{N}, \mathrm{N}$ & & 0.00400944 & 9.01014583 & 249.4113 & & & & & $3,477,600.00$ \\
\hline & $\mathrm{N}, \mathrm{N}$ & & 0.00222288 & 21.2067222 & 449.8673 & & & & & Total \\
\hline & $Y(-3)$ & OEM & & & & & & & & $4,936,920.00$ \\
\hline 125 & $\mathrm{~N}, \mathrm{~N}$ & & 0.00474022 & 8.60053207 & 210.9607 & \multirow{4}{*}{0} & \multirow{4}{*}{$19,352,400$} & \multirow{4}{*}{$201,091,000$} & \multirow{4}{*}{$4 \%$} & $1,012,129.49$ \\
\hline & $\mathrm{N}, \mathrm{N}$ & & 0.00406917 & 8.79920821 & 245.7507 & & & & & $2,212,800.00$ \\
\hline & $\mathrm{N}, \mathrm{Y}$ & & 0.00224995 & 20.2781039 & 444.4538 & & & & & Total \\
\hline & $Y(-3)$ & OEM & & & & & & & & $3,224,929.49$ \\
\hline \multirow[t]{4}{*}{128} & $\mathrm{~N}, \mathrm{~N}$ & & 1 & & & \multirow{4}{*}{0} & \multirow{4}{*}{$21,899,200$} & \multirow{4}{*}{$200,169,000$} & \multirow{4}{*}{$7 \%$} & $\$$ \\
\hline & $\mathrm{N}, \mathrm{N}$ & & 2 & & & & & & & $\$$ \\
\hline & $\mathrm{N}, \mathrm{N}$ & & 3 & & & & & & & Total \\
\hline & $\mathrm{N}$ & OEM & & & & & & & & $\$$ \\
\hline 95 & $N, Y$ & & 0.0003148 & 11.3430854 & 3176.662 & \multirow{4}{*}{0} & \multirow{4}{*}{$20,529,700$} & \multirow{4}{*}{$201,501,000$} & \multirow{4}{*}{$4 \%$} & $533,601.51$ \\
\hline & $\mathrm{N}, \mathrm{N}$ & & 0.0040134 & 9.03012313 & 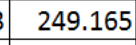 & & & & & $3,196,800.00$ \\
\hline & $\mathrm{N}, \mathrm{N}$ & & 0.0022332 & 21.3859106 & \begin{tabular}{|l|l|}
547.7873 \\
\end{tabular} & & & & & Total \\
\hline & $\mathrm{N}$ & OEM & & & & & & & & $3,730,401.51$ \\
\hline 126 & $\mathrm{~N}, \mathrm{~N}$ & & 0.00468085 & 8.68444487 & 213.6364 & \multirow{4}{*}{0} & \multirow{4}{*}{$20,348,800$} & \multirow{4}{*}{$202,398,000$} & \multirow{4}{*}{$4 \%$} & $613,569.49$ \\
\hline & $\mathrm{N}, \mathrm{N}$ & & 0.00403172 & 8.75549416 & 248.0329 & & & & & $5,349,600.00$ \\
\hline & $\mathrm{N}, \mathrm{Y}$ & & 0.00219129 & 20.4442068 & 456.3516 & & & & & Total \\
\hline & $\mathrm{N}$ & OEM & & & & & & & & $5,963,169.49$ \\
\hline 93 & $N, Y$ & & 0.00031564 & 11.35352 & 3168.159 & \multirow{4}{*}{0} & \multirow{4}{*}{$21,550,700$} & \multirow{4}{*}{$201,305,000$} & \multirow{4}{*}{$3 \%$} & $118,611.00$ \\
\hline & $\mathrm{N}, \mathrm{N}$ & & 0.00401308 & 8.85987219 & 249.1851 & & & & & $2,726,400.00$ \\
\hline & $N, Y$ & & 0.00223019 & 20.441109 & 448.3921 & & & & & Total \\
\hline & $\mathrm{N}$ & OEM & & & & & & & & $2,845,011.00$ \\
\hline
\end{tabular}

Table 5.9: Case 1 Optimal BCP Choices, According to Discrete-Event Simulation Results

After additional testing, data surfaced depicting the 'Sales' results varying in direct

correlation with the amount of demand that happened to be randomly generated and not

necessarily in correlation to the type of response plans implemented, and this measure was 
eliminated from analysis. The findings demonstrated a need to include the cost of implementation in the calculation and exclude any figures corresponding to change in sales. Cost of implementation was calculated according to the average inventory that was recorded during the simulation runs. 'Net Savings' were then recalculated (Figure 5.3). For further decision support, a graphical comparison of the costs according to simulation results was created (Figure 5.4).

\begin{tabular}{l} 
Net Savings $2=$ \\
{$[($ Unmet Demand BCP 128) - (Unmet Demand BCP Y)] $* \$ 2.40$ profit/unit } \\
\hline - BCP Y Cost of Implementation
\end{tabular}

Figure 5.3: Formula for Net Savings 2 (Revised)

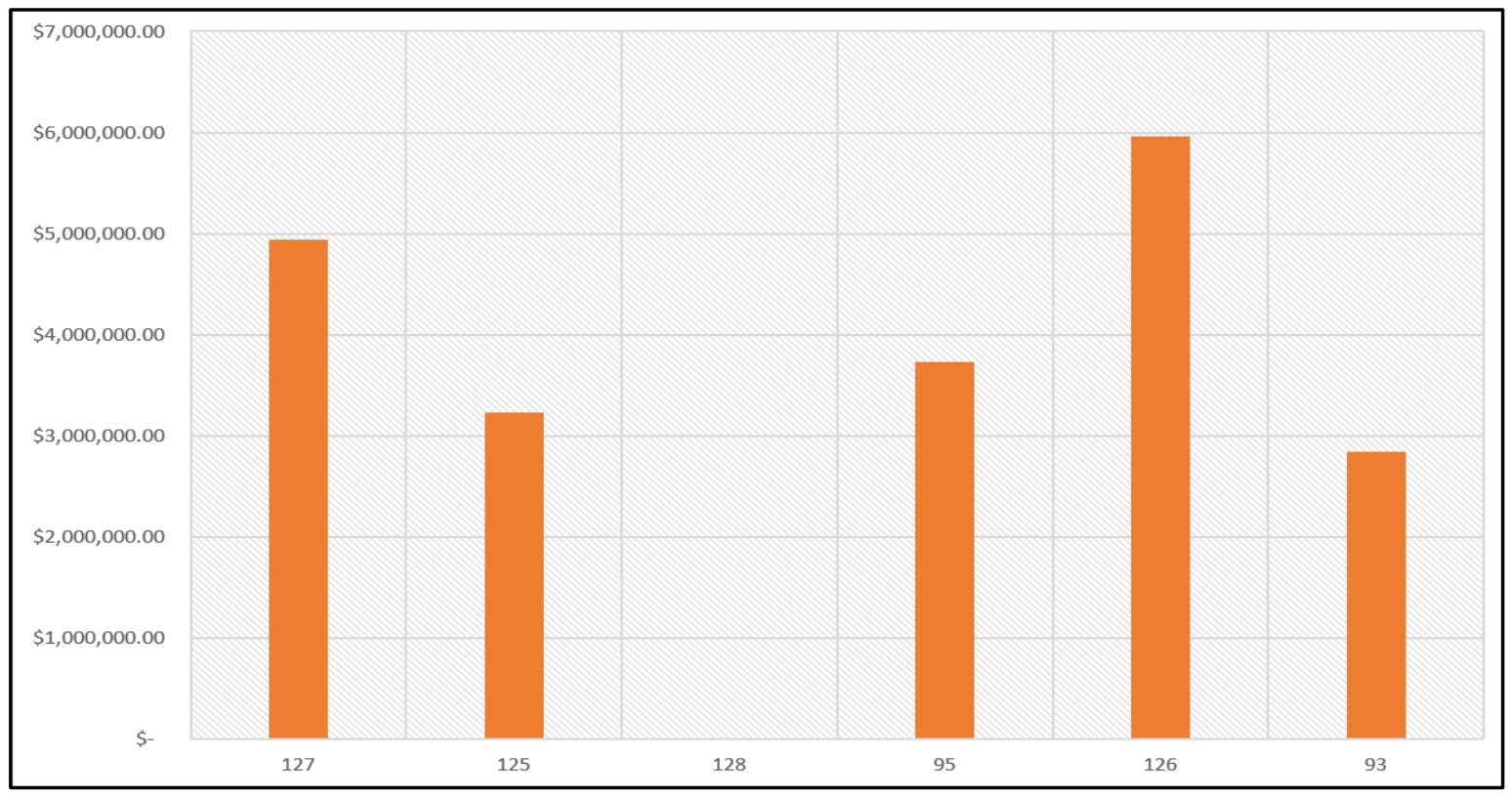

Figure 5.4: Case 1 Graphical Comparison of Optimal BCP net savings 
Case 1A

Case 1A, a revision of Case 1 was performed in order to assess the results of different cost parameters when running the BCP Choice Model. Results from Case 1 showed a strong preference for all choices that included a change in the OEM inventory policy, due to the high dollar savings the cost formulation gave. Further, in Case 1 a preference to not change the inventory policy at supplier sites was apparent due to the high cost parameters associated with choosing this action.

Therefore, a readjustment of these costs was made eliminating the dollar savings at the OEM completely and reducing the cost of having a supplier hold additional inventory to ten percent of what the original Case 1 model specified $(\$ 66,000$ as opposed to $\$ 660,000$ per site per year). Holding three days extra inventory at a supplier site costs the OEM $\$ 230,400$ per year, a value that assumes that the suppliers' costs of holding inventory will transfer directly to the OEM.

The changes to cost parameters yielded the following changes to optimal BCP choices (Table 5.10) as compared to the top choices from original testing (Table 5.11). Worth noting is that while BCP 127 remained in the top six choices (only changing inventory at the OEM site and no other response), it was not the first choice. Also the remaining choices in Case 1A were different than in the original Case 1 results. Thus variability due to cost parameter accuracy was proved. 


\begin{tabular}{|c|c|c|c|c|c|c|c|c|c|c|c|c|c|}
\hline BCP & \multicolumn{2}{|c|}{ Savings } & \multicolumn{2}{|c|}{ Cost } & \multicolumn{2}{|c|}{ Net Savings } & \multirow{2}{*}{$\begin{array}{l}\text { Node1 } \\
\text { /Respo } \\
\text { nseC } \\
\text { Y } \\
\end{array}$} & \multirow{2}{*}{$\begin{array}{l}\text { Node1 } \\
\text { /Respo } \\
\text { nseD } \\
\text { N } \\
\end{array}$} & \multirow{2}{*}{$\begin{array}{l}\text { Node2 } \\
\text { /Respo } \\
\text { nseC } \\
\text { N } \\
\end{array}$} & \multirow{2}{*}{$\begin{array}{l}\text { Node2 } \\
\text { /Respo } \\
\text { nseD } \\
\mathrm{N} \\
\end{array}$} & \multirow{2}{*}{$\begin{array}{l}\text { Node3 } \\
\text { /Respo } \\
\text { nseC } \\
\text { Y } \\
\end{array}$} & \multirow{2}{*}{$\begin{array}{l}\text { Node3 } \\
\text { /Respo } \\
\text { nseD } \\
\text { Y } \\
\end{array}$} & \multirow{2}{*}{$\begin{array}{l}\text { OME } \\
\text { Inventory } \\
\text { Change } \\
\mathrm{N} \\
\end{array}$} \\
\hline 58 & $\$$ & $8,767.975$ & $\$$ & - & $\$$ & $8,767.98$ & & & & & & & \\
\hline 128 & $\$$ & (106.588) & $\$$ & - & $\$$ & $(106.59)$ & $\mathrm{N}$ & $\mathrm{N}$ & $\mathrm{N}$ & $\mathrm{N}$ & $\mathrm{N}$ & $\mathrm{N}$ & $\mathrm{N}$ \\
\hline 95 & $\$$ & $9,346.828$ & $\$$ & $14,198.49$ & $\$$ & $(4,851.67)$ & $\mathrm{N}$ & Y & $\mathrm{N}$ & $\mathrm{N}$ & $\mathrm{N}$ & $\mathrm{N}$ & $\mathrm{N}$ \\
\hline 126 & $\$$ & 957.564 & $\$$ & $6,590.51$ & $\$$ & $(5,632.95)$ & $\mathrm{N}$ & $\mathrm{N}$ & $\mathrm{N}$ & $\mathrm{N}$ & $\mathrm{N}$ & $\mathrm{Y}$ & $\mathrm{N}$ \\
\hline 127 & $\$$ & $(7,260.257)$ & $\$$ & - & $\$$ & $(7,260.26)$ & $\mathrm{N}$ & $\mathrm{N}$ & $\mathrm{N}$ & $\mathrm{N}$ & $\mathrm{N}$ & $\mathrm{N}$ & $\mathrm{Y}$ \\
\hline 93 & $\$$ & $12,606.582$ & $\$$ & $20,789.00$ & $\$$ & $(8,182.42)$ & $\mathrm{N}$ & $\mathrm{Y}$ & $\mathrm{N}$ & $\mathrm{N}$ & $\mathrm{N}$ & $\mathrm{Y}$ & $\mathrm{N}$ \\
\hline
\end{tabular}

Table 5.10: Case 1A Choice Model Results

\begin{tabular}{|c|c|c|c|c|c|c|c|c|c|c|c|}
\hline ВCP & Sav & & Cost & Net Savings & $\begin{array}{l}\text { Node1 } \\
\text { /Respo } \\
\text { nseC }\end{array}$ & $\begin{array}{l}\text { Node1 } \\
\text { /Respo } \\
\text { nseD }\end{array}$ & $\begin{array}{l}\text { Node2 } \\
\text { /Respo } \\
\text { nseC }\end{array}$ & $\begin{array}{l}\text { Node2 } \\
\text { /Respo } \\
\text { nseD }\end{array}$ & $\begin{array}{l}\text { Node3 } \\
\text { /Respo } \\
\text { nseC }\end{array}$ & $\begin{array}{l}\text { Node3 } \\
\text { /Respo } \\
\text { nseD }\end{array}$ & $\begin{array}{l}\text { OME } \\
\text { Inventory } \\
\text { Change }\end{array}$ \\
\hline 127 & $\$$ & $(7,260.257)$ & $\$(691,200.00)$ & $\$ 683,939.74$ & $\mathrm{~N}$ & $\mathrm{~N}$ & $\mathrm{~N}$ & $\mathrm{~N}$ & $\mathrm{~N}$ & $\mathrm{~N}$ & $\mathrm{Y}$ \\
\hline 125 & $\$$ & $(2,331.066)$ & $\$(684,609.49)$ & $\$ 682,278.42$ & $\mathrm{~N}$ & $\mathrm{~N}$ & $\mathrm{~N}$ & $\mathrm{~N}$ & $\mathrm{~N}$ & $\mathrm{Y}$ & $\mathrm{N}$ \\
\hline 96 & $\$$ & $2,413.492$ & $\$(677,001.51)$ & $\$ 679,415.00$ & $\mathrm{~N}$ & $\mathrm{Y}$ & $\mathrm{N}$ & $\mathrm{N}$ & $\mathrm{N}$ & $\mathrm{N}$ & $\mathrm{Y}$ \\
\hline 88 & $\$$ & $14,309.251$ & $\$(664,708.94)$ & $\$ 679,018.19$ & $\mathrm{~N}$ & Y & $\mathrm{N}$ & Y & $\mathrm{N}$ & $\mathrm{N}$ & $\mathrm{Y}$ \\
\hline 94 & $\$$ & $4,886.542$ & $\$(670,411.00)$ & $\$ 675,297.54$ & $\mathrm{~N}$ & Y & $\mathrm{N}$ & $\mathrm{N}$ & $\mathrm{N}$ & $\mathrm{Y}$ & $\mathrm{Y}$ \\
\hline 86 & $\$$ & $16,158.221$ & $\$(658,118.43)$ & $\$ 674,276.65$ & $\mathrm{~N}$ & Y & $\mathrm{N}$ & Y & $\mathrm{N}$ & $\mathrm{Y}$ & $\mathrm{Y}$ \\
\hline
\end{tabular}

Table 5.11: Case 1 Choice Model Results

\section{Case 1B}

The results of the Case 1 discrete-event simulations runs did not show any unmet demand (demand entities emptied into the unmet demand sink) due to the fact that the inventory level policy provided a large enough buffer to prevent lost sales. However, unmet demand is one of the most important KPIs in this model. Therefore, a theoretical case was required to show the effectiveness of the simulation model in assessing responses if unmet demand were to have occurred in the base model.

Case 1B had the same setup as Case 1 with a few differences. The OEM inventory level was set to fourteen days of production, as opposed to 40 days production, and the 'OEM inventory change' response choice was eliminated, resulting in 64 response combinations, as opposed to 128 to be tested. Finally, the cost parameter for more inventory held at a supplier was 
decreased to five percent of the cost implementation in the original Case 1 BCP Choice Model because doing so seemed to reflect reality more, to assume that the cost of having a supplier hold more inventory would be a small fraction of the actual cost to the supplier of holding more inventory.

\section{Case 1B Results}

According to the specified change in risk parameters corresponding to each response, and under the lower cost parameters for inventory, the choice model yielded the following top results (Table 5.12). As expected, response combinations which included holding one day more inventory at any given supplier were at the top of the list due to the fact that the cost parameters for doing so was decreased. Further, no savings or cost parameters were taken into account for changing the amount of inventory held at the OEM and thus the top choices were not influenced by this category.

\begin{tabular}{|c|c|c|c|c|c|c|c|c|c|c|c|c|}
\hline BCP & & & $\mathrm{Cc}$ & & & Savings & $\begin{array}{l}\text { Node1 } \\
\text { /Respo } \\
\text { nseC }\end{array}$ & $\begin{array}{l}\text { Node1 } \\
\text { /Respo } \\
\text { nseD }\end{array}$ & $\begin{array}{l}\text { Node2 } \\
\text { /Respo } \\
\text { nseC }\end{array}$ & $\begin{array}{l}\text { Node2 } \\
\text { /Respo } \\
\text { nseD }\end{array}$ & $\begin{array}{l}\text { Node3 } \\
\text { /Respo } \\
\text { nseC }\end{array}$ & $\begin{array}{l}\text { Node3 } \\
\text { /Respo } \\
\text { nseD }\end{array}$ \\
\hline 24 & $\$$ & $23,192.10$ & $\$$ & $7,360.00$ & $\$$ & $15,832.10$ & $Y$ & $N$ & $Y$ & $N$ & $N$ & $N$ \\
\hline 22 & $\$$ & $24,780.72$ & $\$$ & $11,040.00$ & $\$$ & $13,740.72$ & $Y$ & $N$ & $Y$ & $\mathrm{~N}$ & $Y$ & $\mathrm{~N}$ \\
\hline 23 & $\$$ & $24,359.19$ & $\$$ & $13,950.51$ & $\$$ & $10,408.68$ & Y & $\mathrm{N}$ & $Y$ & $N$ & $\mathrm{~N}$ & $Y$ \\
\hline 31 & $\$$ & $12,402.56$ & $\$$ & $3,680.00$ & $\$$ & $8,722.56$ & $Y$ & $N$ & $\mathrm{~N}$ & $N$ & $N$ & $N$ \\
\hline 29 & $\$$ & $15,470.89$ & $\$$ & $7,360.00$ & $\$$ & $8,110.89$ & $Y$ & $N$ & $N$ & $\mathrm{~N}$ & $Y$ & $\mathrm{~N}$ \\
\hline 21 & $\$$ & $25,712.00$ & $\$$ & $17,630.51$ & $\$$ & $8,081.49$ & $Y$ & $\mathrm{~N}$ & $Y$ & $N$ & $Y$ & $Y$ \\
\hline
\end{tabular}

Table 5.12: Case 1B Choice Model Results

Analysis in Simio under the above-stated fourteen-day OEM inventory policy showed the following results (Table 5.13), and cost analysis of these results was performed (Table 5.14).

Crafting the simulation to model only a fourteen-day inventory policy at the OEM produced the results of existent unmet demand. (Note that the quantities shown in Table 5.13 are in thousands 
of units). Thus, it was possible to take profit loss due to unmet demand into account when simulating the savings that each BCP combination would cause.

\begin{tabular}{|r|l|l|l|l|l|l|l|}
\hline \multicolumn{2}{|l|}{ Scenario } & Replications & Responses & & \\
\hline$\square$ & Name & Status & Completed & UnmetDemand & AverageInventory & ProductionLoss & ProductionTotal \\
\hline$\square$ & BCP 31 & Idle & 10 of 10 & 211.3 & 4406.4 & 4851.6 & 209971 \\
\hline$\square$ & BCP 24 & Idle & 10 of 10 & 870.7 & 3362 & 5640.5 & 209938 \\
\hline$\square$ & BCP 64 & Idle & 10 of 10 & 1547.6 & 1488 & 7758.6 & 209911 \\
\hline$\square$ & BCP 22 & Idle & 10 of 10 & 438.6 & 3595 & 4045.5 & 209898 \\
\hline$\square$ & BCP 23 & Idle & 10 of 10 & 1277.7 & 4401.4 & 4982.1 & 209931 \\
\hline$\square$ & BCP 29 & Idle & 10 of 10 & 367.9 & 3355.3 & 5153.7 & 209932 \\
\hline$\square$ & BCP 21 & Idle & 10 of 10 & 357.4 & 3848.9 & 4164.6 & 209912 \\
\hline
\end{tabular}

Table 5.13: Case 1B Simulation Results, Simio

Results of the cost analysis (Table 5.14) of the discrete-event simulation of BCPs 31, 24, $22,23,29$, and 21 were calculated according to the difference in average inventory held and the amount of unmet demand avoided, using the average levels of inventory and unmet demand of BCP 64 (Figure 5.5), a response combination of all 'No's, as a comparison. Additionally, the cost of implementation calculated in the Part 1 choice model was subtracted from calculated savings.

Under this formula, the cost analysis showed the optimal BCP for the Case 1B experiment to be BCP 29, with an estimated Net Savings of $\$ 1,330,080$ (Table 5.14), and the second most optimal to be BCP 22, withan estimated Net Savings of $\$ 964,960$. BCP 23, on the other hand, showed an estimated Net Cost of $\$ 1,616,911$, due to considerable increase in average inventory at a given time at the OEM site and a only a small resulting reduction of unmet demand simulated. 


\begin{tabular}{|c|c|c|c|c|c|c|}
\hline $\mathrm{BCP}$ & $\begin{array}{l}\text { Y/N } \\
\text { Combo }\end{array}$ & $\begin{array}{l}\text { Unmet } \\
\text { Demand } \\
\text { (units) }\end{array}$ & $\begin{array}{l}\text { Average OEM } \\
\text { Inventory }\end{array}$ & & $\begin{array}{l}\text { st (not } \\
\text { luding } \\
\text { aM } \\
\text { entory) }\end{array}$ & $\begin{array}{l}\text { Net Savings } \\
\text { (Unmet } \\
\text { Demand } \\
\text { Savings + } \\
\text { Inventory } \\
\text { Savinas - Cost) }\end{array}$ \\
\hline 24 & YN & 870,700 & $3,362,000$ & $\$$ & $7,360.00$ & $\$ 1,624,560.00$ \\
\hline & YN & & & & & $\$ \quad(1,499,200.00)$ \\
\hline & NN & & & & & $\$ \quad 118,000.00$ \\
\hline 22 & YN & 438,600 & $3,595,000$ & $\$$ & $11,040.00$ & $\$ 2,661,600.00$ \\
\hline & YN & & & & & $\$(1,685,600.00)$ \\
\hline & YN & & & & & $\$ \quad 964,960.00$ \\
\hline 23 & YN & $1,277,700$ & $4,401,400$ & $\$$ & $13,950.51$ & $647,760.00$ \\
\hline & YN & & & & & $\$(2,330,720.00)$ \\
\hline & NY & & & & & $\$(1,696,910.51)$ \\
\hline 31 & YN & 211,300 & $4,406,400$ & $\$$ & $3,680.00$ & $\$ 3,207,120.00$ \\
\hline & NN & & & & & $\$(2,334,720.00)$ \\
\hline & NN & & & & & $\$ \quad 868,720.00$ \\
\hline 29 & YN & 367,900 & $3,355,300$ & $\$$ & $7,360.00$ & $\$ \quad 2,831,280.00$ \\
\hline & NN & & & & & $\$(1,493,840.00)$ \\
\hline & YN & & & & & $\$ 1,330,080.00$ \\
\hline 21 & YN & 357,400 & $3,848,900$ & & $17,630.51$ & $\$ 2,856,480.00$ \\
\hline & YN & & & & & $\$(1,888,720.00)$ \\
\hline & YY & & & & & $\$ \quad 950,129.49$ \\
\hline 64 & NN & $1,547,600$ & $1,488,000$ & & 0 & $\$$ \\
\hline & NN & & & & & $\$$ \\
\hline & $\mathrm{NN}$ & & & & & $\$$ \\
\hline
\end{tabular}

Table 5.14: Case 1B Simulation Results Cost Analysis

Net Savings $3=$
$[($ Unmet Demand BCP 64) - (Unmet Demand BCP Y) $] * \$ 2.40$ profit/unit
$+\left[\right.$ (BCP 64 Ave.OEM Inventory) - (BCP Y Ave.OEM Inventory) ${ }^{*} \$ 2.00(.4)$ holding/unit
- BCP Y Cost of Implementation

Figure 5.5: Formula for Net Savings 3 
Thus, as a proof of concept, Case 1B, which modeled a fourteen-day inventory policy, verified that measuring unmet demand in the discrete-event simulation model serves to show savings achieved by implementing various response scenarios.

Case 2: Inventory Level Sensitivity

The last theoretical case, Case 2, was designed to assess the results of various OEM inventory level policies as modeled in the simulation. In particular, it demonstrated at what inventory level the model shows that no demand goes unmet. Case 2 also explored whether increased inventory and decreased unmet demand are directly correlated. Lastly, Case 2 explored how closely the average inventory level, measured during the simulation, matched the inventory policy, or desired level. Case 2 used parameters from Case 1, including production and demand rates, supplier inventory level and supply network configuration and the baseline (pre-response) risk parameters at servers.

Risk parameters were not altered for Case 2 scenarios in order to isolate the testing of changed inventory policy at the OEM. The simulation model yielded the following results (Table $5.15)$. 


\begin{tabular}{|c|c|c|c|c|c|c|c|c|}
\hline \multicolumn{3}{|c|}{ Scenario } & \multicolumn{2}{|l|}{ Replications } & \multicolumn{4}{|l|}{ Responses } \\
\hline$\square$ & Name & Status & Required & Completed & UnmetDemand & AverageInventory & ProductionLoss & PotentialP \\
\hline$\square$ & 10 days inventory & Idle & 10 & 10 of 10 & 2981.8 & 867.4 & 7933 & 207814 \\
\hline$\square$ & 12 days inventory & Idle & 10 & 10 of 10 & 1771.8 & 1755.2 & 7126.4 & 208924 \\
\hline$\square$ & 14 days inventory & Idle & 10 & 10 of 10 & 1782 & 1658.3 & 7709.1 & 210013 \\
\hline$\square$ & 16 days inventory & Idle & 10 & 10 of 10 & 1214.1 & 2534.7 & 8238.3 & 211149 \\
\hline$\square$ & 18 days inventory & Idle & 10 & 10 of 10 & 699.1 & 3748.8 & 7681.3 & 212268 \\
\hline$\square$ & 20 days inventory & Idle & 10 & 10 of 10 & 1471 & 3673 & 9122.9 & 213414 \\
\hline$\square$ & 22 days inventory & Idle & 10 & 10 of 10 & 1109.9 & 4421.6 & 8934.3 & 214501 \\
\hline$\square$ & 24 days inventory & Idle & 10 & 10 of 10 & 83.7 & 7147.9 & 7717.7 & 215689 \\
\hline$\square$ & 26 days inventory & Idle & 10 & 10 of 10 & 449.8 & 5507.9 & 10342 & 216830 \\
\hline$\square$ & 28 days inventory & Idle & 10 & 10 of 10 & 49 & 7499 & 9199 & 217943 \\
\hline$\square$ & 30 days inventory & Idle & 10 & 10 of 10 & 277.4 & 8377.5 & 9473.1 & 219046 \\
\hline$\square$ & 32 days inventory & Idle & 10 & 10 of 10 & 0 & 9702.1 & 8229.4 & 220148 \\
\hline$\square$ & 33 days inventory & Compl... & 10 & 10 of 10 & 0 & 10877.1 & 7465.7 & 220692 \\
\hline$\square$ & 34 days inventory & Compl... & 10 & 10 of 10 & 0 & 11502.3 & 8058.7 & 221296 \\
\hline$\square$ & 23 days inventory & Compl... & 10 & 10 of 10 & 127.6 & 5074.6 & 8316.2 & 215028 \\
\hline$\square$ & 25 days inventory & Compl... & 10 & 10 of 10 & 256.1 & 6987.8 & 8486.6 & 216238 \\
\hline$\square$ & 21 days inventory & Compl... & 10 & 10 of 10 & 0 & 4769.1 & 8063.7 & 208379 \\
\hline$\nabla$ & 19 days inventory & Compl... & 10 & 10 of 10 & 588.9 & 4351.5 & 7323.8 & 207219 \\
\hline
\end{tabular}

Table 5.15: Case 2, OEM Inventory Policy Scenario Results, Simio

Results (Table 5.15) showed that as expected, increased inventory policy, modeled by a larger inventory buffer limit in the model and greater ramp-up time, caused for lower amounts of unmet demand. However, unmet demand and inventory level were not directly proportional. Further, the average amount of inventory held at the OEM in the simulation is an average of 11.68 days-worth of inventory lower than the initial inventory policy set-up. This is worth noting because while the policy might have been to hold 24 days of inventory at the OEM, an average of about 13 days of inventory were held in simulation.

The cost of holding inventory was calculated using the average simulated inventory as opposed to the amount specified by the policy. An analysis of the ten to thirty days production inventory policies is shown (Table 5.16), indicating the optimal inventory level for the network. 
The highest net savings occurred in the case of the 21-day inventory policy, which simulated runs that had an average of 8.64 days inventory at any given time. The 21 -day inventory policy was one of several policies of which the result of simulation was zero unmet demand; however, it was estimated to cause the greatest net savings because in it, the lowest amount of inventory was held, reducing costs.

\begin{tabular}{|c|c|c|c|c|c|c|}
\hline \multirow[b]{2}{*}{ Policy } & \multirow[b]{2}{*}{ Unmet Demand } & \multicolumn{4}{|c|}{ As compared to 6 days inventory } & \multirow[b]{2}{*}{ Net Savings } \\
\hline & & $\%$ Unmel & ry (days & Savings & Cost & \\
\hline 6 days inventory & $7,032,600.00$ & $3.49 \%$ & 1.59 & $\$$ & $\$$ & $\$$ \\
\hline 8 days inventory & $4,092,900.00$ & $2.02 \%$ & 0.87 & $\$ 7,055,280.00$ & $\$(318,080.00)$ & $\$ 7,373,360.00$ \\
\hline 10 days inventory & $2,981,800.00$ & $1.48 \%$ & 1.57 & $\$ 9,721,920.00$ & $\$ \quad(6,640.00)$ & $\$ 9,728,560.00$ \\
\hline 12 days inventory & $1,771,800.00$ & $0.88 \%$ & 3.18 & $\$ 12,625,920.00$ & $703,600.00$ & $\$ 11,922,320.00$ \\
\hline 14 days inventory & $1,782,000.00$ & $0.88 \%$ & 3.00 & $\$ 12,601,440.00$ & $\$ 626,080.00$ & $\$ 11,975,360.00$ \\
\hline 16 days inventory & $1,214,100.00$ & $0.60 \%$ & 4.59 & $\$ 13,964,400.00$ & $\$ 1,327,200.00$ & $\$ 12,637,200.00$ \\
\hline 18 days inventory & $699,100.00$ & $0.35 \%$ & 6.79 & $\$ 15,200,400.00$ & $\$ 2,298,480.00$ & $\$ 12,901,920.00$ \\
\hline 19 days inventory & $588,900.00$ & $0.30 \%$ & 7.88 & $\$ 15,464,880.00$ & $\$ 2,780,640.00$ & $\$ 12,684,240.00$ \\
\hline 20 days inventory & $1,471,000.00$ & $0.73 \%$ & 6.65 & $\$ 13,347,840.00$ & $\$ 2,237,840.00$ & $\$ 11,110,000.00$ \\
\hline 21 days inventory & - & $0.00 \%$ & 8.64 & $\$ 16,878,240.00$ & $\$ 3,114,720.00$ & $\$ 13,763,520.00$ \\
\hline 22 days inventory & $1,109,900.00$ & $0.55 \%$ & 8.01 & $\$ 14,214,480.00$ & $\$ 2,836,720.00$ & $\$ 11,377,760.00$ \\
\hline 23 days invenotry & $127,600.00$ & $0.06 \%$ & 9.19 & $\$ 16,572,000.00$ & $\$ 3,359,120.00$ & $\$ 13,212,880.00$ \\
\hline 24 days inventory & $83,700.00$ & $0.04 \%$ & 12.95 & $\$ 16,677,360.00$ & $\$ 5,017,760.00$ & $\$ 11,659,600.00$ \\
\hline 25 days inventory & $256,100.00$ & $0.13 \%$ & 12.66 & $\$ 16,263,600.00$ & $\$ 4,889,680.00$ & $\$ 11,373,920.00$ \\
\hline 26 days inventory & $449,800.00$ & $0.22 \%$ & 9.98 & $\$ 15,798,720.00$ & $\$ 3,705,760.00$ & $\$ 12,092,960.00$ \\
\hline 27 days inventory & - & $0.00 \%$ & 11.72 & $\$ 16,878,240.00$ & $\$ 4,474,800.00$ & $\$ 12,403,440.00$ \\
\hline 28 days inventory & $49,000.00$ & $0.02 \%$ & 13.59 & $\$ 16,760,640.00$ & $\$ 5,298,640.00$ & $\$ 11,462,000.00$ \\
\hline 30 days inventory & $277,400.00$ & $0.14 \%$ & 15.18 & $\$ 16,212,480.00$ & $\$ 6,001,440.00$ & $\$ 10,211,040.00$ \\
\hline 32 days inventory & - & $0.00 \%$ & 17.58 & $\$ 16,878,240.00$ & $\$ 7,061,120.00$ & $\$ 9,817,120.00$ \\
\hline 33 days inventory & - & $0.00 \%$ & 19.70 & $\$ 16,878,240.00$ & $\$ 8,001,120.00$ & $\$ 8,877,120.00$ \\
\hline 34 days inventory & - & $0.00 \%$ & 20.84 & $\$ 16,878,240.00$ & $\$ 8,501,280.00$ & $\$ 8,376,960.00$ \\
\hline
\end{tabular}

Table 5.16: Comparison of Net Savings under Various Inventory Policies

Case 2 proved the value of testing a variety of inventory policy scenarios and showed that inventory policy and ability to meet demand do not have a completely linear relationship, another case for the need to test setups in discrete-event simulation. Because both Cases 1B and 2 showed 
noteworthy results, the author asserts that an ideal model would have the functionality of testing multiple response solutions at once, including an analysis in the trend of inventory policy change.

\section{Comparison of BCP Choice Model Results and Simulation Results}

Important to observe are the differences between the savings estimated by the 'rough cut' BCP Choice Model and the results of the Simio simulation model. For Case 1A, a side-by-side comparison of these outputs (Table 5.17) must be observed.

\begin{tabular}{|c|c|c|c|c|}
\hline \multicolumn{2}{|c|}{ BCP Configuration } & \multirow{2}{*}{\multicolumn{2}{|c|}{\begin{tabular}{|l|}
\multicolumn{1}{|c}{ Analysis } \\
Net Savings (OEM \\
Inventory \\
Savings/Cost+Profit \\
Gain/Loss-Cost) \\
\end{tabular}}} & \multirow[b]{2}{*}{$\begin{array}{l}\text { Choice Model } \\
\text { Simulated } \\
\text { NetSavings }\end{array}$} \\
\hline $\mathrm{BCP}$ & Y/N Combo & & & \\
\hline \multirow[t]{4}{*}{127} & $\mathrm{~N}, \mathrm{~N}$ & $\$$ & $351,200.00$ & \\
\hline & $\mathrm{N}, \mathrm{N}$ & $\$$ & - & \\
\hline & $\mathrm{N}, \mathrm{N}$ & Total & & \\
\hline & $Y(-3)$ & $\$$ & $351,200.00$ & $\$ 418,770.83$ \\
\hline \multirow[t]{4}{*}{125} & $\mathrm{~N}, \mathrm{~N}$ & $\$$ & $729,920.00$ & \\
\hline & $\mathrm{N}, \mathrm{N}$ & $\$$ & - & \\
\hline & $N, Y$ & Total & & \\
\hline & $Y(-3)$ & $\$$ & $723,329.49$ & $\$ 413,868.19$ \\
\hline \multirow[t]{4}{*}{128} & $\mathrm{~N}, \mathrm{~N}$ & $\$$ & - & \\
\hline & $\mathrm{N}, \mathrm{N}$ & $\$$ & - & \\
\hline & $\mathrm{N}, \mathrm{N}$ & Total & & \\
\hline & $\mathrm{N}$ & $\$$ & - & 10.77 \\
\hline \multirow[t]{4}{*}{95} & $N, Y$ & $\$$ & $(556,840.00)$ & \\
\hline & $\mathrm{N}, \mathrm{N}$ & $\$$ & - & \\
\hline & $\mathrm{N}, \mathrm{N}$ & Total & & \\
\hline & $\mathrm{N}$ & $\$$ & $(571,038.49)$ & $\$(2,283.43)$ \\
\hline \multirow[t]{4}{*}{126} & $\mathrm{~N}, \mathrm{~N}$ & $\$$ & $22,600.00$ & \\
\hline & $\mathrm{N}, \mathrm{N}$ & $\$$ & - & \\
\hline & $N, Y$ & Total & & \\
\hline & $\mathrm{N}$ & $\$$ & $16,009.49$ & 344.20 \\
\hline \multirow[t]{4}{*}{93} & $N, Y$ & $\$$ & $(223,320.00)$ & \\
\hline & $\mathrm{N}, \mathrm{N}$ & $\$$ & - & \\
\hline & $N, Y$ & Total & & \\
\hline & $\mathrm{N}$ & $\$$ & $(244,109.00)$ & $\$(7,574.79)$ \\
\hline
\end{tabular}

Table 5.17: Comparison of Risk Assessment and Simulation Results, Case 1B 
It can be seen that while the BCP Choice Model almost showed the same rankings as the Simio model, in terms of Net Savings, the results from the discrete-event simulation were more extreme than those predicted by the BCP Choice Model algorithm. The various differences in calculated net savings have various reasons for occurring. For BCP 127, the savings due to the change in inventory policy was overestimated in the BCP Choice Model. In the case of BCP 125 , the savings due to the change in inventory policy was underestimated in the BCP Choice Model, and no savings occurred due to sales loss change in the discrete-event simulation as predicted by the BCP Choice Model. For BCP 128, estimated net savings were the most similar because no responses were tested; the only differences were due to variability of Monte Carlo generated parameters. As for BCP 95, inventory held at the OEM was higher than with no policy because risk was reduced, and more inventory costs more. In BCP 126, the inventory held in the discreteevent simulation was lower than the policy, making for the difference in net savings calculated. Finally, in the case of BCP 93, the inventory held at the OEM was higher than with no policy because risk was reduced, and this ended up costing more.

Ultimately, a comparison of the results of the BCP Choice Model and discrete-event simulation shows that the discrete-event simulation, as hypothesized, takes more factors into consideration and provides more trustworthy results. At the same time, it was determined that the amount in Net Savings estimated by the BCP Choice Model are close, by trend, to the simulation results and are indeed of use for providing, as modeled, a 'rough cut' of a large number of possible response combinations. In the next chapter, ideas for future work will be suggested in through which the accuracy and complexity of the BCP Choice Model can be increased. 


\section{Chapter 6 - CLOSING DISCUSSION}

Enterprises with global supply networks are at risk of lost revenue as a result of disruptive disasters at supplier locations. Business Continuity Planning (BCP) to identify, assess and respond to such risk are necessary tasks in the modern supply chain. While this paper specifically looked at the use of discrete-event simulation for managing supply chain disruption risk, an assortment of literature regarding methods to mitigate loss in the event of disruption exists. Breuer, et al. (2013) proposed a combined approach of discrete-event simulation and decision trees, for, "reactive risk management." Schmitt and Singh (2009) created a simulation model that assesses the impact of a supply chain's vulnerability to disruption on customer service. Various parts of Schmitt and Singh (2009) are adopted in the construction of this paper's model.

A framework to support Business Continuity Planning (BCP), both mitigation and contingency, prior to the event of a given disruption was proposed by this paper. A unique methodology was created that incorporates the use of a combinatorial risk index algorithm and a discrete-event simulation model in Simio. Information regarding disaster probabilities was generated from the Global Data Risk Platform tool of the United Nations Office for Disaster Risk

Reduction website. As favored by Schmitt and Singh, Monte Carlo simulation was used to generate multi hazard risk distributions, and Simio software modeled the supply chain network vulnerability to disruption and the impact of response strategies. Cost of implementation, average inventory level, unmet customer demand, and production loss were used for the assessment.

The Risk Index (probability $\mathrm{x}$ impact) was used to evaluate and strategize responses to risks through the $\mathrm{BCP}$ Choice Model, a combinatorial optimization tool which ranked responses 
in order of cost effectiveness. Successive analysis in discrete-event simulation of 'best' BCP scenarios then provided rigorous analysis for use by supply chain management (Figure 3.1).

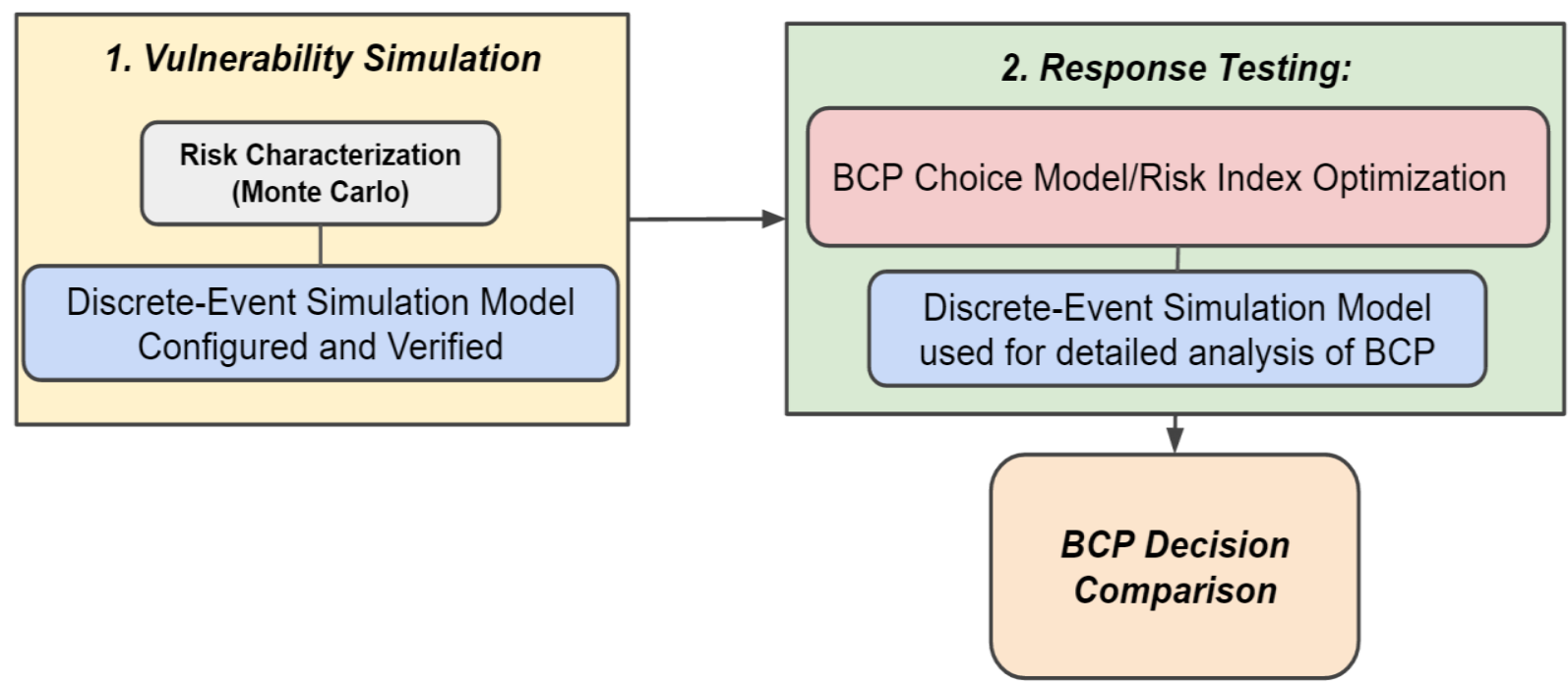

Figure 3.1: Model Flow

Research and testing revealed that discrete-event simulation provides a large variety of useful metrics for assessing the effects of increased risk and/or changes in a supply network configuration (to predict production loss, unmet demand, sales, and average inventory). The testing portion of this study provided a detailed look into the functionality of the methodology proposed in this thesis and confirmed its accuracy.

\section{Findings}

Case 1, modeling a real historic supply chain scenario, proved that the discrete-event simulation model was fit for use and provided a foundation from which a proof of concept was made for the response assessment portion of the methodology. Cases 1A, 1B and 2, theoretical variations on the Case 1 scenario, served to further confirm that the response assessment portion of the model worked under a variety of setups in response implementation cost and inventory 
policies. Ultimately, it was shown that the incorporation of discrete-event simulation into Business Continuity Planning through Risk Index combinatorial optimization is feasible and contributes to the body of knowledge regarding Business Continuity Planning.

\section{Research Limitations and Implications}

Ideally, future research would consider the accuracy of this model by testing multiple company scenarios. Corporate information regarding this topic is limited due to its classified and competitive nature. The decision model developed by this study was tested successfully with a historical business scenario received from a professional in the field. Additional implementation of the model and demonstration of its success will further suggest the strength of combining risk index assessment and discrete-event simulation for BCP decision support.

\section{Future Work}

The author sees opportunity for the incorporation of various methods into the BCP Choice Model that were not developed in this thesis. In particular, a budget constraint could be included in the combinatorial optimization, allowing for further accuracy and functionality in implementation. Further, regarding the accuracy of risk data used, Bayesian analysis could be incorporated, as demonstrated by previous research (Eckle and Burgherr, 2013; Samaddar and Nargundkar, 2010). Finally, the BCP Choice Model could be made more efficient by checking the value of savings minus the cost of implementation for each node/response combination and eliminating all that are less than or equal to 0 dollars, prior to running the optimization.

With regard to implementing BCP decision support, companies would benefit from the creation of a publicly available, updated and audited website which displays a comprehensive details regarding disruption likelihoods and severities around the globe. Such beneficial 
information would be comparable to information found on PreventionWeb but more thorough and audited. Finally, the author suggests that ERP software companies consider integrating discreteevent simulation as a part of supply chain risk management functionality as proposed in this study. 


\section{BIBLIOGRAPHY}

Abo-Hamad, W., \& Arisha, A. (2011). Simulation-optimisation methods in supply chain applications: A review. Irish Journal of Management, 30(2), 95-124. Retrieved from http://ezproxy.lib.calpoly.edu/login?url=http://search.proquest.com/docview/893091559?a $\underline{\text { ccountid }=10362}$

"Basic Country Statistics and Indicators- Japan: Disaster \& Risk Profile - BETA." PreventionWeb. PreventionWeb, 2014. Web. 12 November 2015.

Bereriche, Y., \& Ait-Kade, D. (April 2015). Contingency Design for Reliability in Supply Chain. International Journal of Risk and Contingency Management, archive. Volume 4, Pages 31-44. DOI:10.4018/IJRCM.2015040103 or http://dl.acm.org/citation.cfm?id=2783856

Bimpikis, K., Fearing, D., \& Tahbaz-Salehi, A. (2014). Multi-sourcing and miscoordination in supply chain networks. St. Louis: Federal Reserve Bank of St Louis. Retrieved from http://ideas.repec.org/p/ecl/stabus/3100.html

Breuer, C; Castine, JD; Siestrup, G; Haasis, H. Wildebrand, H. (2013). Risk-Oriented Decision Support in Sensitive Logistics Nodes. Proceedings of the 18th International Symposium on Logistics, 213-221.

Deleris, L., \& Erhun, F. (2005). Risk Management in Supply Chain Networks Using Monte Carlo Simulation. IEEE Simulation Conference, 2005 Proceedings of the Winter. DOI: 10.1109/WSC.2005.1574434

Dumke, Daniel. (2011, May 18). Monte Carlo Simulation to Improve Network Resilience. Retrieved from http://scrmblog.com/review/monte-carlo-simulation-to-improve-network$\underline{\text { resilience. }}$ 
Eckle, P., \& Burgherr, P. (2013). Bayesian data analysis of severe fatal accident risk in the oil chain. Risk Analysis, 33(1), 146-160. doi:http://dx.doi.org/10.1111/j.1539$\underline{6924.2012 .01848 . x}$

Ghadge, A., Dani, S., \& Kalawsky, R. (2012). Supply chain risk management: Present and future scope. International Journal of Logistics Management, 23(3), 313-339. doi:http://dx.doi.org/10.1108/09574091211289200

Grose, V. (1987). Managing Risk : Systematic Loss Prevention for Executives. Englewood Cliffs, N.J.: Prentice-Hall.

Hoyt, R. E., Powell, L. S., \& Sommer, D. W. (2007). Computing Value at Risk: A Simulation Assignment to Illustrate the Value of Enterprise Risk Management. Risk Management and Insurance Review, 10(2), 299. Retrieved from http://ezproxy.lib.calpoly.edu/login?url=http://search.proquest.com/docview/209604289?a countid $=10362$

Hubbard, D. (2010). How to Measure Anything. New Jersey: John Wiley \& Sons, Inc..

Hübner, D., Larsson, T., Wagner, S. M., \& Christ, A. (2014). Costly Supply Chain Disruptions. Industrial Engineer, 46(3), 32-37. Retrieved from http://ezproxy.lib.calpoly.edu/login?url=http://search.proquest.com/docview/1534296841? $\underline{\text { accountid }=10362}$

“Global Risk Data Platform.” UNEP. UNEP/UNISDR, 2013. 10 November 2015. http://preview.grid.unep.ch/index.php?preview=map\&lang=eng Jain, N., Girotra, K., \& Netessine, S. (2013). Managing Global Sourcing: Inventory Performance. Management Science, 60(5). Retrieved from 
http://pubsonline.informs.org/doi/abs/10.1287/mnsc.2013.1816\#.VGbq6RMocE8.mendele y

Jain, S., \& Leong, S. (2005). Stress testing a supply chain using simulation. Proceedings of the 37th Conference on Winter Simulation, 1650-1657. Retrieved from http://portal.acm.org/citation.cfm?id=1162995

Khedr, M. K. (2006). Project risk management using monte carlo simulation. AACE International Transactions, , RI21-RI29,RI210. Retrieved from http://ezproxy.lib.calpoly.edu/login?url=http://search.proquest.com/docview/208172509?a ccountid $=10362$

Klastorin, T., \& Mitchell, G. (2013). Optimal project planning under the threat of a disruptive event. IIE Transactions, 45(1), 68. Retrieved from http://ezproxy.lib.calpoly.edu/login?url=http://search.proquest.com/docview/1115385331? accountid=10362

Kumar, S., \& Nottestad, D. (2012). Supply Chain analysis methodology- Leveraging optimization and simulation software. OR Insight (2013) 26, 87-119. DOI: 10.1057/ori.2012.10

Kyng, T., \& Konstandatos, O. (March 2014). Multivariate Monte-Carlo Simulation and Economic Valuation of Complex Financial Contracts. Spreadsheets in Education, 7(2). Retrieved from http://epublications.bond.edu.au/cgi/viewcontent.cgi?article=1157\&context=ejsie

Lau, C. W., \& Wongsurawat, W. (2013). Crisis management: Western digital's 46-day recovery from the 2011 flood disaster in thailand. Strategy \& Leadership, 41(1), 34-38. doi:http://dx.doi.org/10.1108/10878571311290061 
Manuj, I, \& Mentzer, J. (2008). Global supply chain risk management strategies. International Journal of Physical Distribution \& Logistics Management, Vol. 38 Iss: 3, pp.192 - 223 DOI: http://dx.doi.org/10.1108/09600030810866986

Manuj, I., Mentzer, J., \& Bowers, M. (2009). Improving the rigor of discrete- event simulation in logistics and supply chain research. International Journal of Physical Distribution \& Logistics Management, Vol. 39 Iss: 3, pp.172 - 201. http://dx.doi.org/10.1108/09600030910951692

Matta, A., Li, J., Sahin, E., Lanzarone, E., \& Fowler, J. (Eds.). (2014). Proceedings of the International Conference on HealthCare Systems Engineering (Vol. 61). Cham: Springer International Publishing. http://doi.org/10.1007/978-3-319-01848-5

Oeser, G. (2015). Risk-Pooling Essentials: Reducing Demand and Lead Time Uncertainty. Heidelburg, New York, London: Springer International Publishing.

Ojha, D., \& Gokhale, R. A. (2009). Logistical business continuity planning-scale development and validation. International Journal of Logistics Management, 20(3), 342-359. doi:http://dx.doi.org/10.1108/09574090911002814

Pal, R., Torstensson, H., \& Mattila, H. (2014). Antecedents of organizational resilience in economic crises - an empirical study of Swedish textile and clothing SMEs. International Journal of Production Economics, 147, 410-428. http://doi.org/10.1016/j.ijpe.2013.02.031

Pawar, K. S., Rogers, H. (Eds.) (2013). Proceedings of the 18th International Symposium on Logistics: Resilient Supply Chain in an Uncertain Environment. Nottingham: Centre for Concurrent Enterprise Nottingham University Business School. 
Samaddar, S., \& Nargundkar, S. (2010). Analyzing supply chain disruption risk: A decision analysis framework. Operations Management Education Review, 4, 87-107. Retrieved from

http://ezproxy.lib.calpoly.edu/login?url=http://search.proquest.com/docview/868918464?a countid $=10362$

Schmitt, A., \& Singh, M. (2009) Quantifying Supply Chain Disruption Risk Using Monte Carlo and Discrete-Event Simulation. IEEE Proceedings of the 2009 Winter Simulation Conference (WSC), 1237-1248. DOI: 10.1109/WSC.2009.5429561

Shreve, C. M., \& Kelman, I. (Dec 2014). Does mitigation save? Reviewing cost-benefit analyses of disaster risk reduction. International Journal of Disaster Risk Reduction, 10(A), 213235. http://www.sciencedirect.com/science/article/pii/S2212420914000661 or doi:10.1016/j.ijdrr.2014.08.004

Supply Chain Risk Leadership Council. (2013). SCRLC Emerging Risks in the Supply Chain [White paper]. Retrieved from http://www.scrlc.com/articles/Emerging_Risks_2013_feb_v10.pdf

Sheffi, Yossi. (2005). The Resilient Enterprise. Cambridge, London: The MIT Press. Sheffi, Y., \& Lynn, B. (2014). Systemic Supply Chain Risk. The Bridge (Fall), 22-29.

Sodhi, M. S. B.-G. T. C. S. (2012). Researchers' Perspectives on Supply Chain Risk Management. Production and Operations Management. Retrieved from http://search.proquest.com/docview/922784588?accountid=10362\&title=Researchers\%27 +Perspectives+on+Supply+Chain+Risk+Management\#.VLamunu-iqc.gmail 
Swaminathan, J., Smith, S., \& Sadeh, N. M. (1998). Modeling supply chain dynamics: A multiagent approach. Decision Sciences, (Summer), 607-632. Retrieved from http://search.proquest.com.ezproxy.lib.calpoly.edu/abicomplete/docview/198104310/34EF $\underline{\text { 52C8DD744E43PQ/2?accountid=10362 }}$

Terzi, S., \& Cavalieri, S. (2004). Simulation in the supply chain context: a survey. Computers in Industry, 53(1), 3-16. http://doi.org/10.1016/S0166-3615(03)00104-0

Tillet L, S. (2000). Agencies Go Online With Incident Management -- Workflow application provides links to electronic maps for more coordinated event response. InternetWeek, 21. Retrieved from http://search.proquest.com/abicomplete/docview/226907441/4D69CAC5869E4A57PQ/1? accountid $=10362$

Tomlin, B. (2006). Mitigation and Contingency Strategies for Managing Supply Chain Disruption Risks. Management Science, 52(5), 639-657. Retrieved from http://ezproxy.lib.calpoly.edu/login?url=http://search.proquest.com/docview/213187146?a countid $=10362$

Tummala, R., \& Schoenherr, T. (2011). Assessing and managing risks using the Supply Chain Risk Management Process (SCRMP). Supply Chain Management: An International Journal, 16, 474-483. http://doi.org/10.1108/13598541111171165

Van der Zee, D. J, \& Van der Vorst, J G. (2005). A modeling framework for supply chain simulation: Opportunities for improved decision making. Decision Sciences, 36(1), 65-95. Retrieved from 
http://ezproxy.lib.calpoly.edu/login?url=http://search.proquest.com/docview/198113933?a $\underline{\text { ccountid }=10362}$

Wai, L. C. \& Wongsurawat, W. (2013). Case Crisis management: Western Digital's 46-day recovery from the 2011 flood disaster in Thailand. Strategy and Leadership, 41(1), 34-38. DOI $10.1108 / 10878571311290062$

Wei; Song, Faishuai; Ye, Feifan. (2013). Order allocation for multiple supply-demand networks within a cluster.

Xiang, W., Song, F., \& Ye, F. (2013). Order allocation for multiple supply-demand networks within a cluster. Journal of Intelligent Manufacturing, Volume 25, Issue 6, pp 1367-1376. DOI: $10.1007 / \mathrm{s} 10845-013-0735-0$ or http://link.springer.com.ezproxy.lib.calpoly.edu/article/10.1007/s10845-013-0735-0\#

Xu, D., Nageshwaraniyer, S. S., Bhardwaj, P., Son, Y., \& Lu, R. (2011). Hierarchical simulationbased planning framework for resource allocation and balanced delay. IIE Annual Conference.Proceedings, 1-8. Retrieved from http://ezproxy.lib.calpoly.edu/login?url=http://search.proquest.com/docview/1190332135? accountid=10362

Yanikara, F. S., Kuhl, M. E., \& Thorn, B. K. (2014). Comparing reverse logistics network configurations using simulation. IIE Annual Conference.Proceedings, 2864-2873. Retrieved from http://ezproxy.lib.calpoly.edu/login?url=http://search.proquest.com/docview/1622308778? accountid=10362 


\section{APPENDICES}

\section{Appendix A}

\section{Map 1: From “Dynamic” PreventionWeb Map}

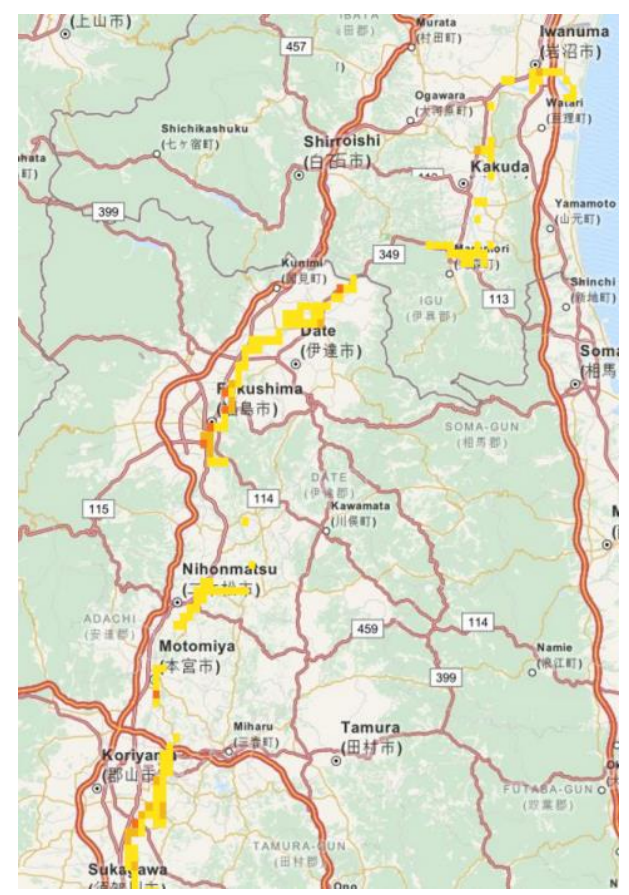

$$
\begin{aligned}
& \text { Floods Pop. Exp. } \\
& \text { Less than } 30 \text { (people } \\
& 30-100 \text { (people/year } \\
& 100-300 \text { (people/ye: } \\
& 300-1,000 \text { (people/y } \\
& \text { More than } 1,000 \text { (pec } \\
& \text { No data }
\end{aligned}
$$


Map 2: From Past Events: Volcanic Eruptions (PreventionWeb)

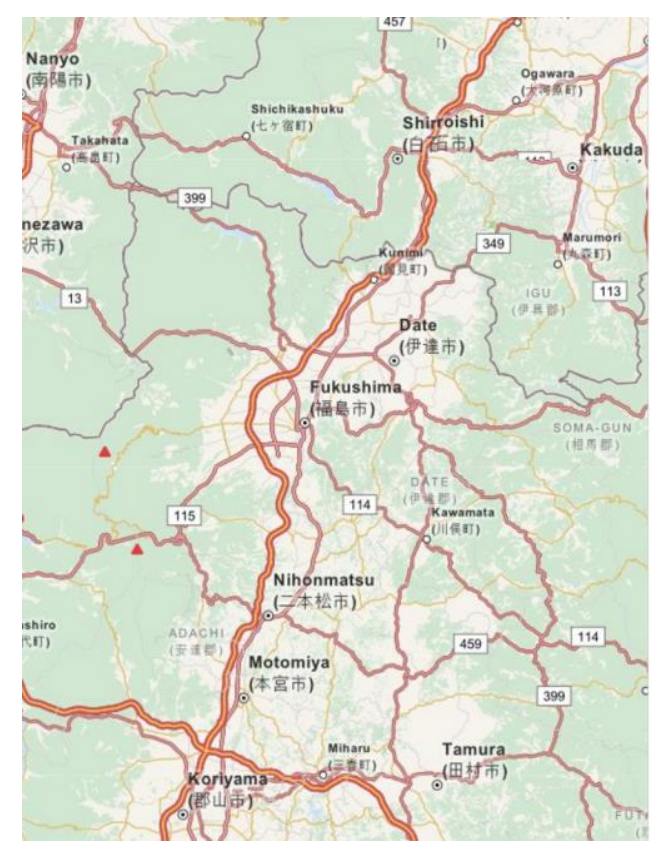

(Information about these volcanoes gathered from http://volcano.si.edu/region.cfm?rn=8.)

Map 3: Landslides

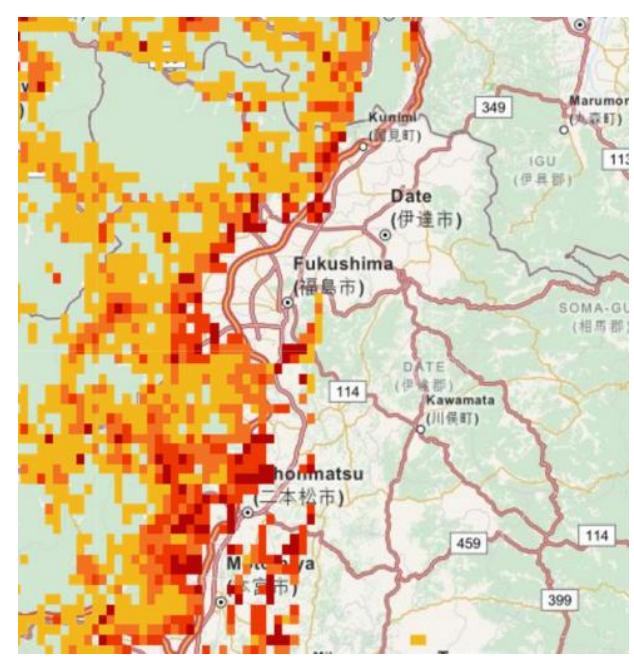




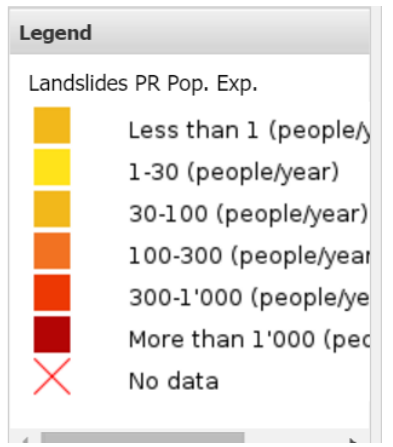

\section{Map 4: Tropical Cyclones}

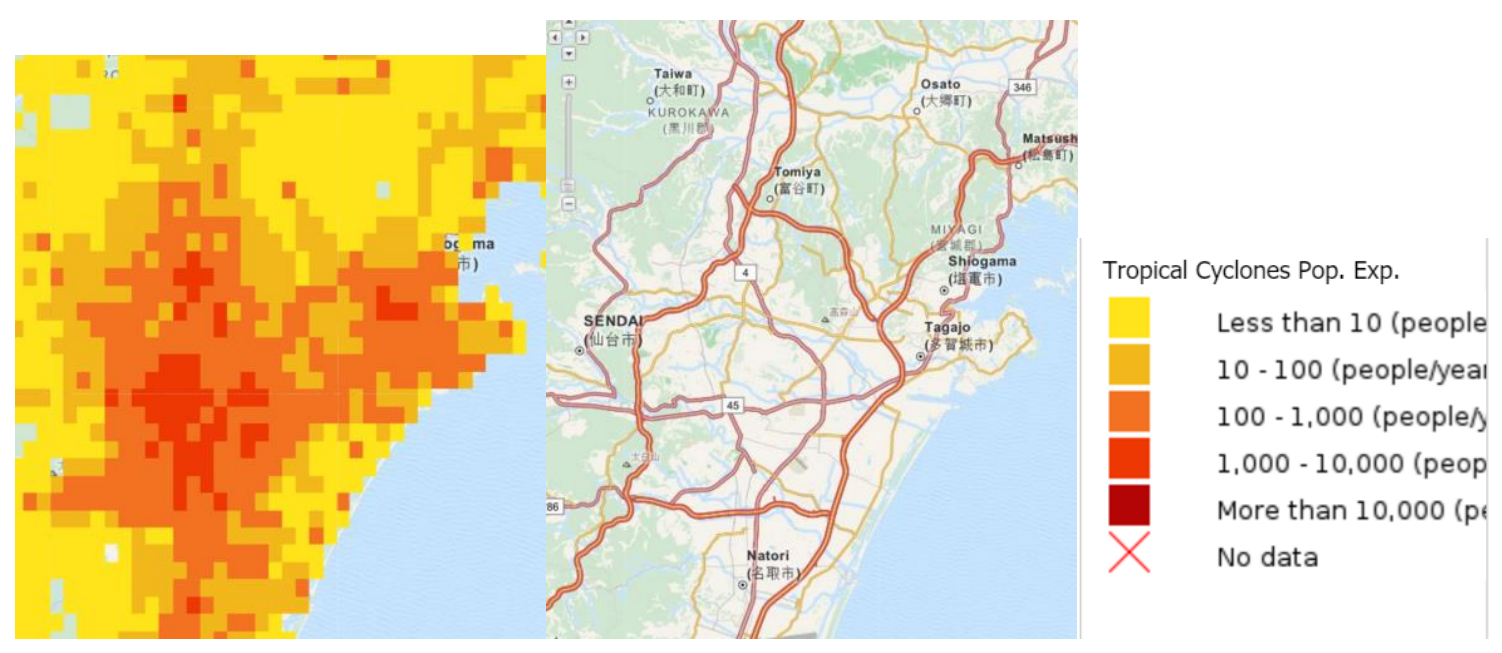

Map 5: Storm Surge

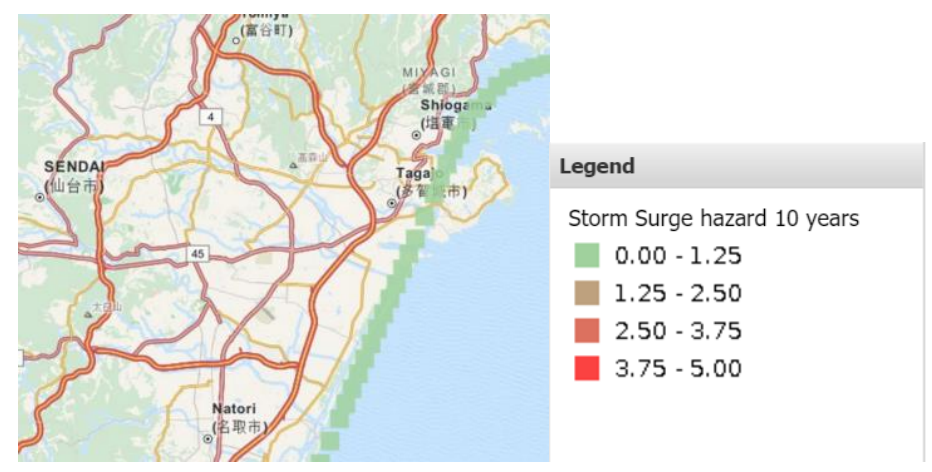


Map 6: Tsunami

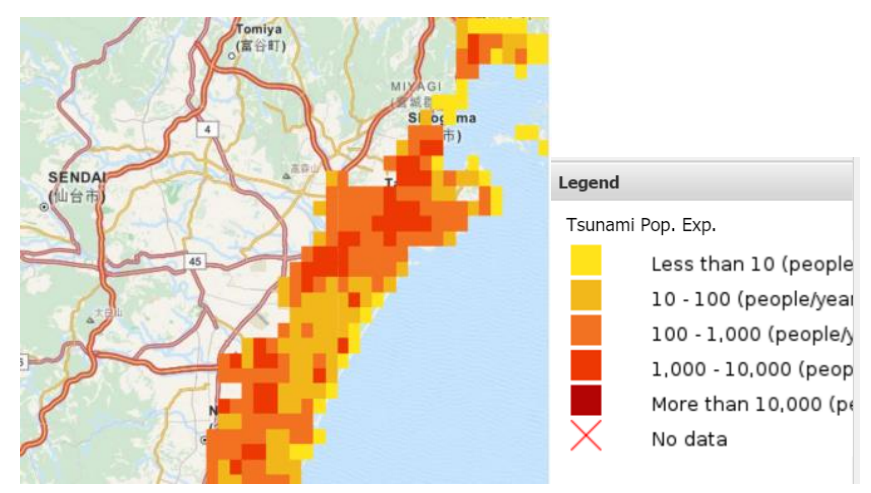

